\title{
TID- 15482
}

\section{A STUDY OF GAMMA-RAY PHOTOCONDUCTIVITY IN ORGANIC DIELECTRIC MATERIALS}

\author{
by \\ S. E. Harrison \\ Radiation Effects Division-II \\ Sandia Corporation \\ Albuquerque, New Mexico
}

\begin{abstract}
A Thesis
Submitted in Partial Fulfillment of the Requirements for the Degree of Master of Science in Electrical Engineering
\end{abstract}

The University of New Mexico 


\section{DISCLAIMER}

This report was prepared as an account of work sponsored by an agency of the United States Government. Neither the United States Government nor any agency Thereof, nor any of their employees, makes any warranty, express or implied, or assumes any legal liability or responsibility for the accuracy, completeness, or usefulness of any information, apparatus, product, or process disclosed, or represents that its use would not infringe privately owned rights. Reference herein to any specific commercial product, process, or service by trade name, trademark, manufacturer, or otherwise does not necessarily constitute or imply its endorsement, recommendation, or favoring by the United States Government or any agency thereof. The views and opinions of authors expressed herein do not necessarily state or reflect those of the United States Government or any agency thereof. 


\section{DISCLAIMER}

Portions of this document may be illegible in electronic image products. Images are produced from the best available original document. 


\section{ABSTRACT}

The gamma-ray photoconductivities of polyethylene, polystyrene, polyvinylchloride, polypropylene, Teflon, nylon, Kel-F, and three thermosetting resins denoted as Epoxy 1478-1, 1478-3, and 1478-22 have been measured. The measurements were made at steady-state gamma-ray intensities ranging from $1.0 \mathrm{rad}\left(\mathrm{H}_{2} \mathrm{O}\right) / \mathrm{min}$ to $3.0 \times 10^{5} \mathrm{rads}\left(\mathrm{H}_{2} \mathrm{O}\right) / \mathrm{min}$ and at controlled temperatures ranging from $90^{\circ} \mathrm{F}$ to $140^{\circ} \mathrm{F}$. Conductivity changes resulting from the steady-state gamma-ray exposures were measured continuously throughout the exposure and after the exposure. The exposure period was of sufficient duration to allow all samples to achieve an equilibrium conductivity value. The conductivity was found to exhibit distinct features in three time intervals: interval 1 is where photoconductivity is responding to a step increase in radiation intensity; interval 2 is where the photoconductivity has reached an equilibrium value whose magnitude is defined by radiation intensity and temperature; and interval 3 is where the conductivity is recovering upon sample removal from the gamma-ray environment. The time required during interval 1 for the conductivity to reach the equilibrium value of interval 2 is defined as the rise time $\left(\boldsymbol{\tau}_{\mathbf{r}}\right)$ and was experimentally found to decrease with increased irradiation intensity according to the relationship

$$
\tau_{\mathbf{r}}=\tau_{\mathbf{r}} \dot{\mathrm{R}}^{-\mu}
$$

The equilibrium conductivity values of interval 2 give a dependence of photoconductivity on irradiation intensity at a given temperature which is characterized to good approximation in one or more regions, within which conductivity $(\sigma)$ is expressed as

$$
\sigma=\sigma_{0}^{\circ} \dot{\mathrm{R}}^{\delta}
$$

Experimental values of $\delta$ range from 0.00 to 2.72. Conductivity decays with time $(t)$ from an equilibrium value $\left(\sigma_{\text {eq }}\right)$ after abruptly stopping radiation exposure. The photoconductivity decay is characterized to good approximation by

$$
\sigma(t)=\sigma_{\text {eq }}\left[A e^{-t / \tau_{1}}+B e^{-t / \tau_{2}}\right]
$$


where $\tau_{1}$ and $\tau_{2}$ are two distinct decay constants. Conductivity was observed to vary with temperature under both dark and radiation-induced conductivity conditions according to the relationship

$$
\sigma=\sigma_{0} \mathrm{e}^{-\mathrm{E} / \mathrm{kT}}
$$

The thermal activation energy $(E)$ is lowered by irradiation except for Epoxy 1478-1 which has one intensity interval, within which $\mathrm{E}$ is unchanged. 


\section{ACKNOWLEDGMENTS}

The author wishes to express his indebtedness to A. W. Snyder, J. W. Easley, and W. W. Grannemann* for helpful discussions and stimulating suggestions throughout the work; to P. J. Thoma and R. F. Moll for discussions and advice relating to materials selection; to the project engineers and operations personnel of the Engineering Test Reactor, Phillips Petroleum Company, Idaho Falls, Idaho, for excellent support and cooperation during the experimental phases of this work (in particular D. R. Alvord, J. Dunbar, and A. Holman); and to P. F. Proulx for his full-time assistance in the support of all phases of this work. University of New Mexico, Albuquerque, New Mexico. 
CHAPTER I

INTRODUCTION

CHAPTER II

EXPERIMENTAL

CHAPTER III

RESULTS AND DISCUSSION 11

Conductivity Versus Time 11

Rise Time $\quad 11$

Conductivity Versus Intensity 13

Conductivity Versus Temperature $\quad 20$

Conductivity Versus Accumulated Exposure 21

Conductivity Recovery $\quad 21$

CHAPTER IV

SUMMARY 26

$\begin{array}{ll}\text { BIBLIOGRAPHY } & 27\end{array}$

APPENDIX A

MECHANISMS OF GAMMA-RAY INTERACTION

WITH MATTER

APPENDIX B

TYPICAL ELECTRON TRANSITIONS IN PHOTOCONDUCTORS

APPENDIX C

CHEMICAL STRUCTURE OF SELECTED ORGANIC

MATERIALS

$\begin{array}{ll}\text { Polyethylene } & 36\end{array}$

$\begin{array}{ll}\text { Polystyrene } & 36\end{array}$

$\begin{array}{ll}\text { Polypropylene } & 37\end{array}$

$\begin{array}{ll}\text { Nylon } & 37\end{array}$

$\begin{array}{ll}\text { Polytetrafluoroethylene (Teflon) } & 37\end{array}$

$\begin{array}{ll}\text { Polyvinylchloride (PVC) } & 38\end{array}$

Polychlorotrifluoroethylene (Kel-F) 38

Epoxy Formulations $\quad 38$

$\begin{array}{ll}\text { Epoxy 1478-1 } & 38\end{array}$

Epoxy 1478-3 39

Epoxy 1478-22 39

APPENDIX D

SAMPLE IDENTIFICATION AND THICKNESS $\quad 40$ 


\section{CONTENTS (continued)}

APPENDIX E

DISCUSSION OF LEAKAGE CURRENTS

APPENDIX F

MATHEMATICAL FORMULATION OF THE PHOTO-

CONDUCTIVITY PROCESS IN SINGLE CRYSTAL PHOTOCONDUCTORS

APPENDIX G

MODELS WHICH FIT MEASURED PHOTOCONDUCTIVITY

PHENOMENA

APPENDIX $\mathrm{H}$

RATE OF IONIZATION

APPENDIX I

THERMAL ACTIVATION ENERGIES AND PHOTOCONDUCTIVITY ACTIVATION ENERGIES 


\section{LIST OF ILLUSTRATIONS}

Figure

1. Test Configuration and Encapsulated Unit

2. Abbreviated Drawing of Fuel Element Array, ETR-Canal, Water Filled Test Column, Sample, and Sample Positioning with Respect to Mid-Plane

3. Conductivity Versus Time for Polystyrene After Three Consecutive Exposures at an Intensity of $1.9 \times 10^{5} \mathrm{rads}$ $\left(\mathrm{H}_{2} \mathrm{O}\right) / \mathrm{min}$

4. $\quad$ - $n$ - In Plot of Rise Time, Sec., Versus Gamma-Ray Intensity, rads $\left(\mathrm{H}_{2} \mathrm{O}\right) / \mathrm{min}$, for Epoxy 1478-1, Polyethylene, and Polystyrene

5. Conductivity Versus Intensity for Epoxy 1478-1 at 100, 120 , and $140^{\circ} \mathrm{F}$

6. Conductivity Versus Accumulated Exposure for Ten Materials Measured 24 Hours After Each Exposure, at $500 \mathrm{~V}$, After $60 \mathrm{Sec}$. of Electrification, and at $90^{\circ} \mathrm{F}$

7. Recovery Curves at $130^{\circ} \mathrm{F}$ After Exposure to $2.0 \times 10^{5}$ rads $\left(\mathrm{H}_{2} \mathrm{O}\right) / \mathrm{min}$

8. Ascending and Descending Curves of Conductivity

Versus Gamma-Ray Intensity for Polyethylene,

Polystyrene, and Epoxy 1478-1

A-1. Absorption Coefficient Versus Photon Energy for Carbon

B-1. Common Electron Transitions in Photoconductors

F-1. Simplified Energy Level Diagram

G-1. Exponential Trap Distribution

G-2. Uniform Trap Distribution

G-3. Discontinuous Band Structure of Amorphous and SemiCrystalline Organic Insulators as Suggested by Fowler

I-1. Thermal Activation Energy and Photoconductivity Activation Energy for Epoxy 1478-1

I-2. Thermal Activation Energy and Photoconductivity Activation Energy for Polyethylene

I-3. Thermal Activation Energy and Photoconductivity Activation Energy for Polystyrene 


\section{LIST OF TABLES}

TABLE I Summary of $\mu$ and $\boldsymbol{\tau}_{\mathbf{r}}^{\prime}$ as Defined by $\tau_{\mathbf{r}}=\tau_{\mathbf{r}} \dot{\mathrm{R}}^{-\mu}$

TABLE II Measured Values of $\delta$ and $\sigma_{0}^{\circ}$ for Ten Materials as Defined by $\sigma=\sigma_{0}^{\circ} \dot{R}^{\delta}$

TABLE III Thermal Activation Energies and Photoconductivity Activation Energies 


\section{CHAPTER I -- INTRODUCTION}

The photoconductivity pr uperties of some organic dielectric materials exposed to gamma radiation were measured at gamma-ray intensities in the range of $1.0 \mathrm{rad} *\left(\mathrm{H}_{2} \mathrm{O}\right) / \mathrm{min}$ to $3.0 \times 10^{5} \mathrm{rads}\left(\mathrm{H}_{2} \mathrm{O}\right) / \mathrm{min}$. The source of gamma radiation was the fission product inventory of reactor fuel elements. Measurements of the photoconductivities were made at controlled temperatures. Polystyrene, polyethylene, polyvinylchloride, polypropylene, Teflon, nylon, Kel-F, and three epoxy formulations denoted as 1478-1, 1478-3, and 1478-22 were studied. Polyethylene, polystrene, and Epoxy 1478-1 were studied more extensively than the others. The temperature dependence of the magnitude of the photoconductivity was measured at 100,120 , and $140^{\circ} \mathrm{F}$ for polyethylene, polystyrene, and Epoxy 1478-1. Photoconductivities in the other materials were measured at $90^{\circ} \mathrm{F}$.

The dependence of equilibrium photoconductivity on irradiation intensity $(\dot{R})$ at a given temperature in insulating materials can be characterized to good approximation in one or more regions of $\dot{\mathrm{R}}$, within which conductivity $(\sigma)$ is expressed as

$$
\sigma=\sigma_{0}^{\bullet} \dot{R}^{\delta}
$$

where $\sigma_{o}^{\circ}$ and $\delta$ are empirical constants. Photoconductivity of this form is based on the model of Rose ${ }^{1}$ and has been found by Fowler ${ }^{2}$ and by Coleman ${ }^{3}$ to exist at low intensities $\left(<10^{2} \mathrm{rads}\left(\mathrm{H}_{2} \mathrm{O}\right) / \mathrm{min}\right)$ for the thermalplastic materials of this work.

*rad $\left(\mathrm{H}_{2} \mathrm{O}\right)=100$ ergs of energy absorbed per gram of $\left(\mathrm{H}_{2} \mathrm{O}\right)=6.24 \times 10^{13}$ electron volts of energy absorbed per gram of $\left(\mathrm{H}_{2} \mathrm{O}\right)$.

${ }^{1}$ Rose, A., "An Outline of Some Photoconductive Processes, " $\underline{\text { RCA }}$ Review, 12, 362 (1951).

${ }^{2}$ Fowler, J. F., "X-ray Induced Conductivity in Insulating Materials," Proceedings of the Royal Society of London, 464 (1956).

${ }^{3}$ Coleman, J. H. , 23rd Annual Meeting, Conference on Electrical Insulation, Sponsored by National Academy of Science-National Research Council, 1955. 
The photoconductivity properties of extremely low conductivity $\left(<10^{15} \mathrm{ohm}^{-1} \mathrm{~cm}^{-1}\right)$ organic dielectric materials constitute a relatively unexplored, unresolved field. Basic investigations of the photoconductivity mechanisms have been restricted largely to single-crystal, high-purity inorganic materials. The photoconductivities of organic polymers reveal a quantitative behavior similar in form to that of the photoconductivities of inorganic crystalline structures and suggest the conclusion that the fundamental processes in both material types are in a general way related. The most distinctive structural difference between inorganic crystals and organic polymers is the amorphous and semicrystalline nature of the latter. Semicrystalline materials are those which have crystalline regions formed interspersed in the amorphous mass of the polymer chain. According to recent theoretical work by Lauritzen and Hoffman ${ }^{4}$ the organic crystalline unit cells are formed by chain folding, i. e., such crystalline regions consist of uniform lamellae with the organic molecules approximately normal to the plane of the lamellae in a sharply, regularly folded configuration.

Photoconductivity was first observed by $\mathrm{Smith}^{5}$ in 1873 when he found that a selenium resistor could not be depended upon to have the same resistance under light intensity variations (daylight or darkness). The observations of photoconductivity which followed this initial discovery were sporadic and not until early in the twentieth century did researchers find that many materials exhibited photoconductivity properties. The first comprehensive study of the photoconductivity process was conducted by Gudden and Pohl and their contemporaries between 1920 and 1930, principally with zinc, sulfide, diamond, and alkali halides. They showed that light absorption, the excitation of luminescence by light, and the excitation of photoconductivity by light all had a similar dependence on the wavelength of the light for a given material. Of

\footnotetext{
${ }^{4}$ Lauritzen, J. I., and Hoffman, J. D., "Theory of Formation of Polymer Crystals with Folded Chains in Dilute Solution, " J. Res. N.B.S., $64 \mathrm{~A}, 73$ (1960).
}

5 Smith, W., "Effects of Light on Selenium During the Passage of an Electric Current," Nature, 7, 303 (1873). 
prime importance to the interpretation of the phenomenon, they establish the quantum nature of "primary photocurrents" in the photoconductivity process by showing that one electric charge passes between electrodes for each light photon absorbed. 6 In addition to primary photocurrents, Gudden and Pohl found many photoconductive effects of comparatively mysterious origin which they attributed to "secondary photocurrents". In 1937, Hilsch and Pohl ${ }^{7}$ proposed a theory for such currents. Even then it took several years for these secondary photocurrents to become accepted as a common and legitimate property of photoconductors. In 1952, Moss ${ }^{8}$ summarized the current state of thinking about photoconductivity. Numerous publications exist which are pertinent to photoconductivity and a concentrated discussion of the field as a whole exists in four references. . $^{8-11}$

The term "photoconductivity" includes electrical conductivity changes associated with the absorption of gamma-ray, X-ray, ultraviolet, visible light, or infrared photons. Since photoconductivity is concerned chiefly with the rate of excitation and recombination of electrons, it is an artificial separation to exclude excitation by alpha, beta, or other nuclear particles even though they are normally described by the term "bombardment induced conductivity" rather than photoconductivity. Any material is considered to be a photoconductor if the absorption of energy from photons or particles changes the conductivity. Basically, the photoconductivity processes involve the

${ }^{6}$ Gudden, B. , and Pohl, R., "Photoelectric Conductivity", Phys. Zeits., 23, 417 (1922).

${ }^{7}$ Hilsch, R., and Pohl, R., Phys. Zeits, 108, 55 (1953).

${ }^{8}$ Moss, T. S., Photoconductivity in the Elements, Butterworth's Scientific Publications, London, 1952.

${ }^{9}$ Proceedings of the IRE, 43, 1819 (1955).

${ }^{10}$ Photoconductivity Conference, John Wiley and Sons, Inc., 1956.

${ }^{11}$ Bube, R. H., Photoconductivity of Solids, John Wiley and Sons, Inc., New York, 1960. 
absorption of energy from radiation, the excitation of charge carriers from nonconducting states to conducting states, and the return of charge carriers from conducting states to nonconducting states.

There are three principal mechanisms by which gamma rays interact with matter to produce photoconductivity. These mechanisms are photoelectric effect, Compton effect, and pair production. These topics are discussed extensively in many texts, and Appendix A summarizes the salient features of each with appropriate references. The photon-electron interactions frequently produce ionization whereby the incident photon removes an electron from its parent atom or molecule leaving an electron deficiency, i.e., a hole associated with an atom or molecule. The ionized electron may have sufficient kinetic energy to cause secondary ionization and excitation in neighboring atoms where upon subsequent collisions they become sufficiently nonenergetic to become captured by the same or other atomic nuclei. The term "excitation" refers to a process by which an electron is raised to a high energy level but remains bound to its parent nucleus. Excitation can result from direct photon-electron interaction or as a secondary process as indicated above. Typical electron transitions in photoconductors are presented and discussed in Appendix B.

The subject of trapping has a distinct part in explaining the photoconductivity process. Trapping is the spatial confinement of an electron or hole such that the electron or hole is prohibited from moving freely through the material unless supplied with additional thermal or photon energy. In accord with photoconductivity terminology the term "trap" or "trapping" is reserved for centers whose occupancies are dictated by thermal equilibrium exchange with the nearest allowed band, i.e., thermal release of electrons and holes to the conduction and valence bands, respectively. The rate of release depends on temperature according to the relationship exp ( $\mathrm{E} / \mathrm{kT})$ where $E$ is the depth of the trap. A material containing large numbers of deep "traps" may show reduced photoconductivity, and a slow "trap" decay as the carriers are released after removal of the photon source. Those traps which do not have a significant thermal exchange with the nearest allowed band are called "recombination centers." Because of this type of definition, there 
is an inherent vagueness in defining what types of centers are "traps"; in fact, any center can be a "trap" under one condition of photon intensity and temperature, and a recombination center under another condition.

The above, brief discussion draws heavily on current single-crystal photoconductivity theory. This is the most logical starting point for photoconductivity work in insulating materials. Polymer-type organic structures are not so well defined and understood as are high-purity, single-crystal inorganics. Consequently, any basic study of the photoconductivity process in polymer materials is complicated by the completely homogeneous way that the polymer chains are intermingled. The electron energy levels are determined by the molecular and intermolecular forces, and the valence electrons that are dealt with are not necessarily associated with a single atom but are molecular valence electrons. ${ }^{12}$

This thesis is divided into three major chapters as follows: (1) a chapter which presents experimental procedures; (2) a chapter which presents and discusses data on conductivity versus time, conductivity rise time, conductivity versus gamma-ray intensity, conductivity versus temperature, conductivity versus accumulated gamma-ray exposure, and conductivity recovery; and (3) a summary chapter. Nine appendixes are included which contain more detail on certain select topics.

${ }^{12}$ Aftergut, S., and Brown, G. P., General Electric Co., Schenectady, N. Y., Paper given at Conference on Organic Semiconductors, Chicago, April, 1961. 


\section{CHAPTER II -- EXPERIMENTAL}

The chemical structures of the materials used in this investigation are given in Appendix C. Each sample disc tested has been identified in Appendix D, and all figures and tables showing experimental data have the identification of the corresponding sample discs involved.

Each sample disc tested was thoroughly cleaned in alcohol, and aluminum electrodes were vacuum-metalized on the parallel surfaces to insure good electrical contact between the insulator material and the metal electrode. The discs were $10.16 \mathrm{~cm}$ in diameter and $0.119 \mathrm{~cm}$ to $0.368 \mathrm{~cm}$ thick as summarized in Appendix D. For convenience in calculating fringing effects for varying sample thickness, the electrode dimensions were as suggested by ASTM D 257-58. . $^{13}$ For the measurement of conductivity, each disc, along with electrodes and heaters, was encapsulated in a thermalsetting resin by a vacuum process. The test units, as shown in Fig. 1(a), include the disc of dielectric; the electrode system, consisting of a guarded electrode (dia. = $7.91 \mathrm{~cm})$, an extended guard electrode (I.D. $=8.23 \mathrm{~cm}$, O. D. $=10.16 \mathrm{~cm})$, and a bottom electrode (dia. $=10.16 \mathrm{~cm}$ ); two coaxial monitoring cables with the shields connected to the guard electrode; two parallel planes of heating elements located equidistantly above and below the electrodes; leads for heater power; and a thermocouple for control and recording of sample temperature. The encapsulated unit is shown in Fig. 1(b). The encapsulating material (Epoxy 1478-1) was for water proofing and reduction of ionization leakage currents.

The resistance of the sample discs was recorded continuously using a Brown strip-chart recorder driven by a Tera-Ohmmeter. The Tera-Ohmmeter is capable of measuring to $5 \times 10^{15}$ ohms with an accuracy of \pm 3 percent and with a comparative measurement capability of \pm 1 percent. Repeated measurements with the Tera-Ohmmeter, Brown strip-chart recorder, and encapsulated test units revealed a system comparative measurement capability of \pm 8 percent.

\footnotetext{
${ }^{13}$ ASTM Standards, Part 9, D 257-58, 1958, p. 612.
} 
(a) TEST CONFIGURATION

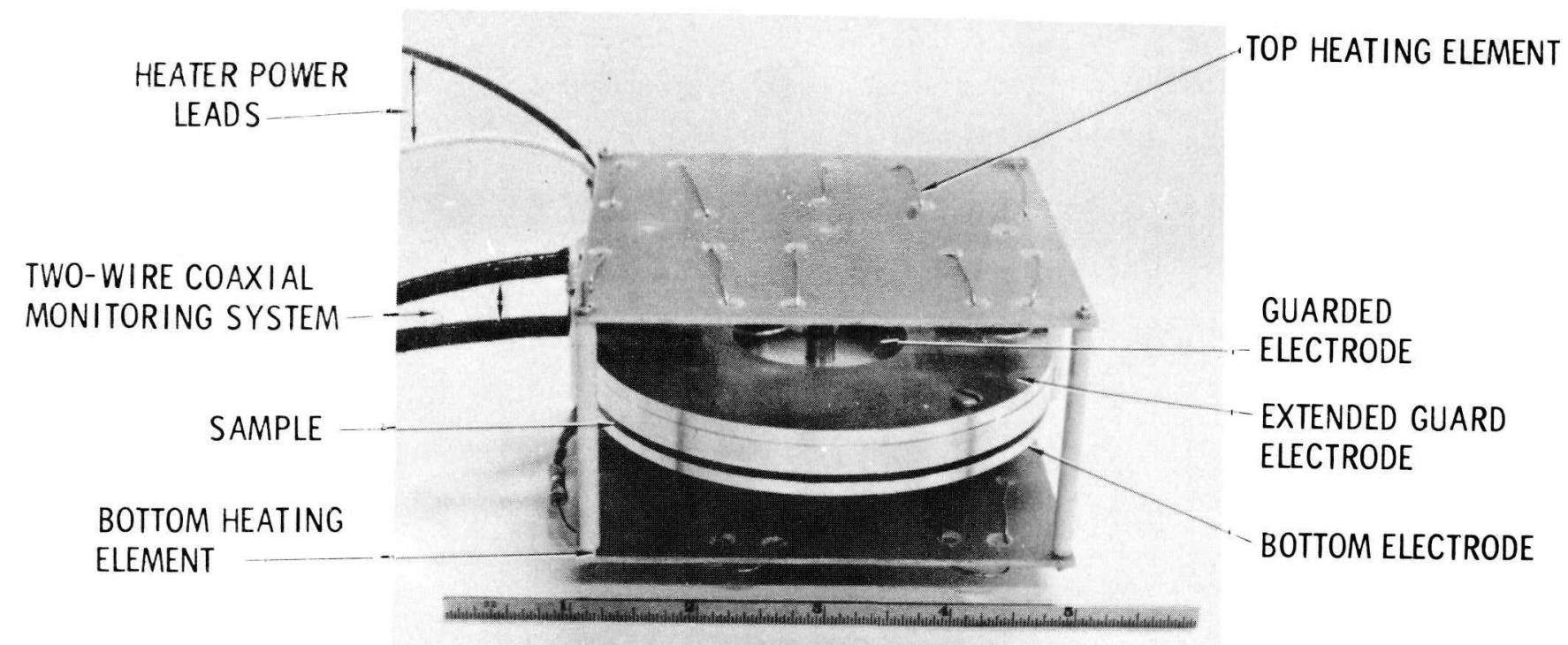

(b) ENCAPSULATED UNIT (MATERIAL - EPOXY 1478-1)

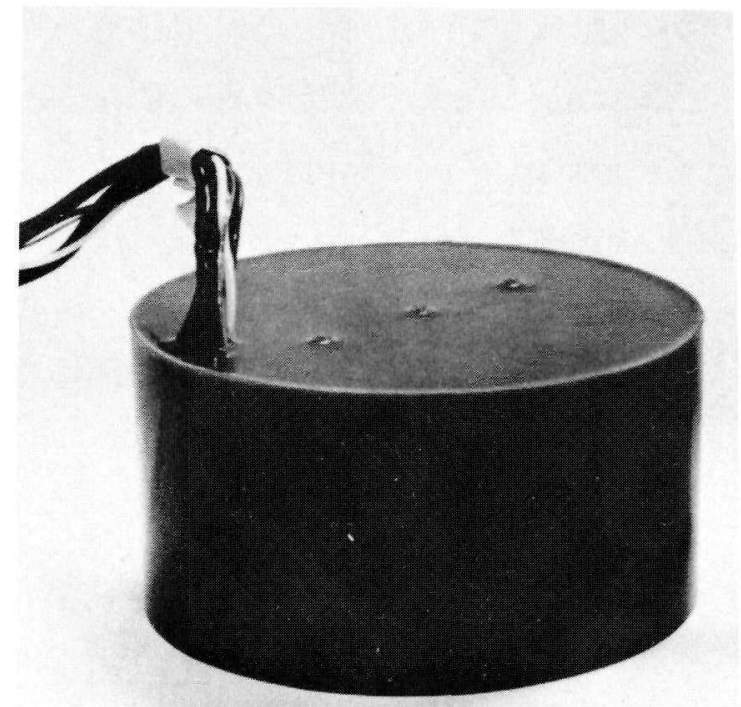

FIG. 1. TEST CONFIGURATION AND ENCAPSULATED UNIT 
The best estimate of the system accuracy is \pm 30 percent. With voltage applied a stabilization time of $1.8 \times 10^{3}$ seconds was observed before data were taken on a given sample.

The built-in heater elements of Fig. 1 gave temperature control from $90^{\circ} \mathrm{F}$ to $160^{\circ} \mathrm{F}, \pm 2^{\circ} \mathrm{F}$.

Gamma-ray intensities, to $3.0 \times 10^{5} \mathrm{rads}\left(\mathrm{H}_{2} \mathrm{O}\right) / \mathrm{min}$, were achieved with spent Engineering Test Reactor (ETR) fuel elements. As shown in Fig. 2, variations in gamma-ray intensity were obtained by positioning the encapsulated samples in a vertical water column at a variable distance, $\ell$, above the midplane at the array of fuel elements. The vertical column is an aluminum tube, 8 inches in diameter and 21 feet high, which is filled with water. Twelve ETR fuel elements were placed in a rectangular array around the base of the column.

Radiation intensities in the water column at the site of a sample were measured with ceric sulfate and ferrous sulfate chemical dosimeters, and additional comparative measurements were made with a graphite ionization chamber (pressure and temperature compensated) inserted into a cavity of a mock encapsulated sample. The chemical dosimeter measurements at the midplane revealed that radial intensity variations over the sample dimensions in the column did not exceed 5 percent; at other locations up the column, the radial variations in intensity were equal to or less than 5 percent.

Ionization leakage current between the measuring electrodes is eliminated by the guard electrode under nonirradiated conditions. However, in the presence of radiation the ionization of air provides a significant conduction path which is parallel to the conduction of the disc of material, thereby giving erroneous conductivity measurements. The successful elimination of leakage currents by encapsulation was assured by experimental measurements. The sufficient condition to assure that the leakage current of the encapsulating material did not contribute to the measurement of the photoconductivity of a material $\mathrm{x}$ is

$$
\frac{I_{\ell, x}}{I_{x}} \leq \frac{I_{0, \ell, x}}{I_{0, x}}
$$




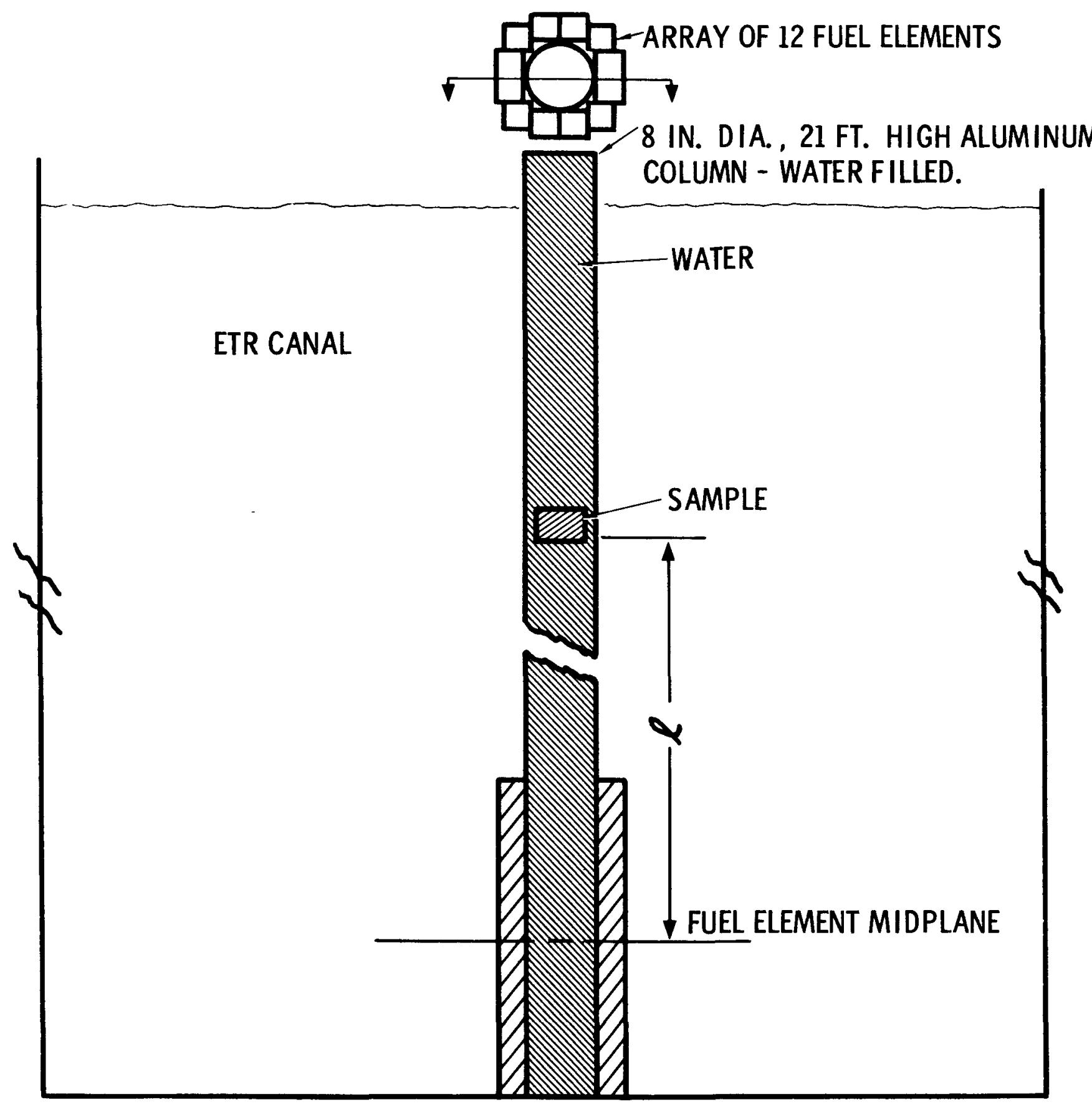

FIG. 2. ABBREVIATED DRAWING OF FUEL ELEMENT ARRAY, ETR-CANAL, WATER FILLED TEST COLUMN, SAMPLE, AND SAMPLE POSITIONING WITH RESPECT TO MID-PLANE. 
where

$$
\begin{aligned}
I_{x}= & \text { the measured photocurrent in the disc of material } x, \\
I_{0, x}= & \text { the measured dark current in the disc of material } x, \\
I_{\ell, x}= & \text { the measured photocurrent in the encapsulating material when } \\
& \text { tested as a disc } x,
\end{aligned}
$$

and $I_{0, \ell, x}=$ the measured dark current in the encapsulating material when tested as a disc $x$.

For every encapsulated sample studied, the sufficient condition of Eq. (2) was satisfied for all levels of the radiation intensity used in this experiment. Appendix E presents the development of Eq. (2). 


\section{CHAPTER III -- RESULTS AND DISCUSSION}

Conductivity Versus Time

Typical data taken of conductivity versus time at a fixed temperature and gamma-ray intensity are shown in Fig. 3. The data are of one sample of polystyrene at $130^{\circ} \mathrm{F}$ and at a gamma-ray intensity of $1.9 \times 10^{5} \mathrm{rads}\left(\mathrm{H}_{2} \mathrm{O}\right) / \mathrm{min}$. The beginning of an exposure is designated as "in" to note that the sample was lowered suddenly into the column to a predetermined intensity; the end of an exposure is designated as "out" to note that the sample was suddenly pulled out of the column to a point of no radiation exposure. The data taken on all materials have distinct features in three time intervals. Interval 1 is where photoconductivity is responding to a step increase in radiation intensity, but the conductivity has not yet achieved equilibrium. Interval 2 is where the conductivity has reached an equilibrium value determined for a specific material by the radiation intensity and temperature of the sample of material. Interval 3 represents the recovery of the conductivity upon removal of the sample from the gamma-ray field. In Fig. 3 it is noted in the third time interval that the magnitude of conductivity is affected by the previous history of exposure of the sample, and that conductivity is observed to increase with increased exposure.

\section{Rise Time}

The significant observation associated with Interval 1 of Fig. 3 is the conductivity rise time, $\boldsymbol{\tau}_{\mathbf{r}}$. The rise time is the time required for the conductivity to reach an equilibrium value defined by the plateau of Interval 2. The plateau represents an equilibrium condition, a function of intensity and temperature, where the rate of generation of free carriers is equaled by the rate of carrier annihilation through recombination, and the rate of capture of free carriers in trapping (metastable) states is equal to the rate of release from trapping states. The rise time indicates that there is a finite interval associated with this equilibrium plateau before which the rate of generation of free carriers exceeds the rate of recombination of free carriers. The rise time decreases with increased intensity. The measured data for Epoxy 1478-1, 


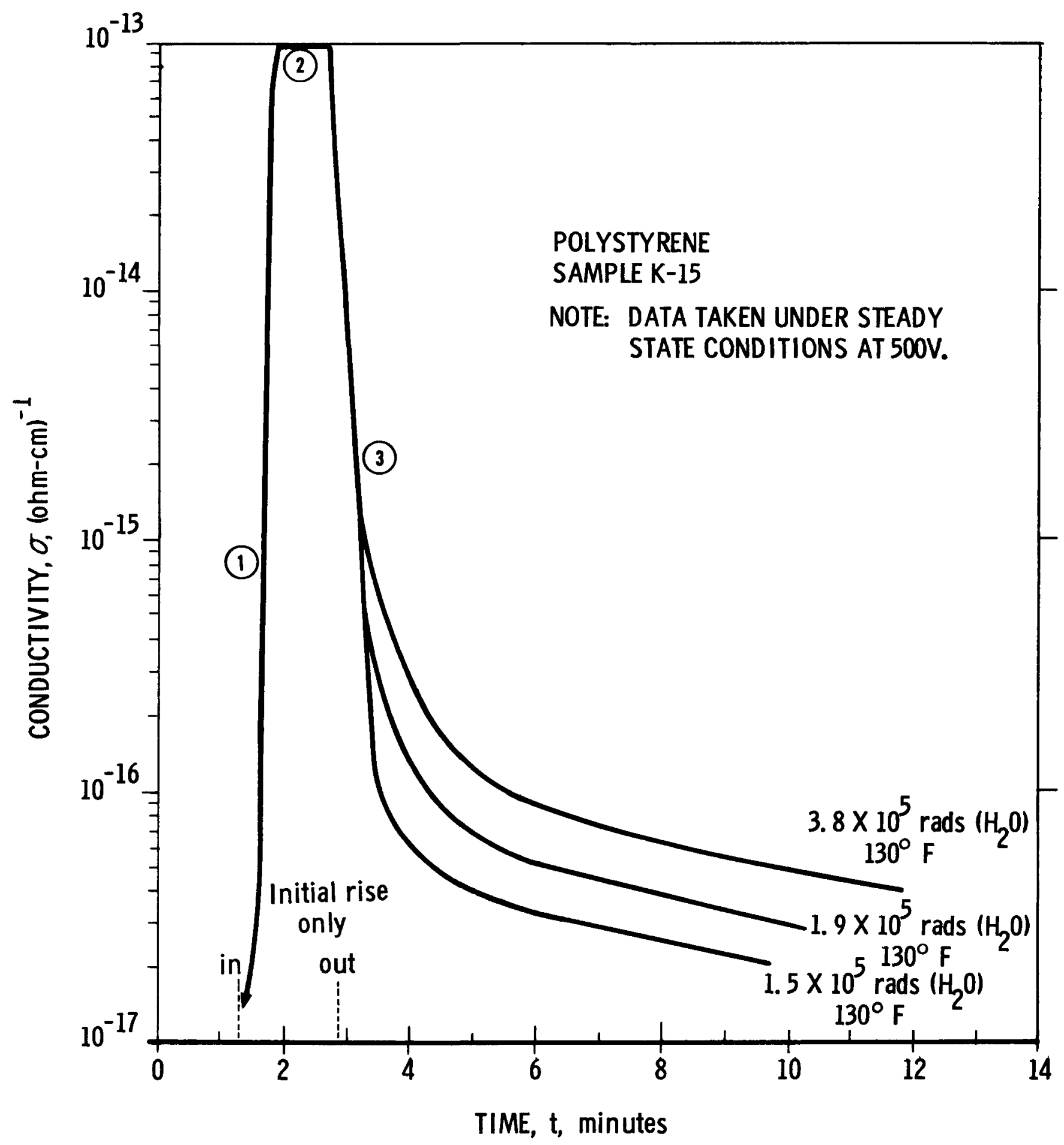

FIG. 3. CONDUCTIVITY VERSUS TIME FOR POLYSTYRENE AFTER THREE CONSECUTIVE EXPOSURES AT AN INTENSITY OF $1.9 \times 10^{5}$ RADS $\left(\mathrm{H}_{2} \mathrm{O}\right) / \mathrm{MIN}$. 
polyethylene, and polystyrene are presented in Fig. 4. A straight line on these $\ln \dot{R}$ versus $\ln \tau_{r}$ plots approximate the data points. The line is represented by the functional relationship

$$
\tau_{r}=\tau_{r}^{\prime} \dot{R}^{-\mu}
$$

where $\tau_{r}^{*}$ and $\mu$ are empirical constants, and are summarized in Table I. The rise times at $10^{1} \mathrm{rads}\left(\mathrm{H}_{2} \mathrm{O}\right) / \mathrm{min}$ for polyethylene and polystyrene are, respectively, 460 seconds and 870 seconds. At $10^{1} \mathrm{rads}\left(\mathrm{H}_{2} \mathrm{O}\right) / \mathrm{min}$, Epoxy 1478-1 does not exhibit an observable increase in conductivity. The rise time at $2.2 \times 10^{5} \mathrm{rads}\left(\mathrm{H}_{2} \mathrm{O}\right) / \mathrm{min}$ for polyethylene, polystyrene, and Epoxy 1478-1 are, respectively, 10 seconds, 6.4 seconds, and 7.4 seconds.

TABLE I

Summary of $\mu$ and $\tau_{r}^{\circ}$ as Defined by $\tau_{\mathbf{r}}=\tau_{\mathbf{r}}^{\bullet} \dot{\mathrm{R}}^{-\mu}$

\begin{tabular}{lcc}
\hline Material & $\mu$ & $\tau_{\mathbf{r}}^{\dot{1}}$ \\
\hline Epoxy 1478-1 & 0.41 & $\mathrm{e}^{7.0}$ \\
Polyethylene & 0.51 & $\mathrm{e}^{7.2}$ \\
Polystyrene & 0.50 & $\mathrm{e}^{7.9}$ \\
\hline
\end{tabular}

Note: $\tau_{r}$ has units of seconds and $\dot{R}$ has units of $\mathrm{rads}\left(\mathrm{H}_{2} \mathrm{O}\right) / \mathrm{min}$.

Conductivity Versus Intensity

The plateaus (interval 2 of Fig. 3) of the continuously measured conductivity-time curves are used to obtain conductivity-intensity curves with temperature as a controlled variable. Typical conductivity-intensity data for Epoxy 1478-1 are shown in Fig. 5. The dependence of photoconductivity on irradiation intensity at a given temperature in all insulating materials studied can be characterized to good approximation in one or more regions of $\dot{R}$, within which conductivity, $\sigma(\mathrm{ohm}-\mathrm{cm})^{-1}$, is expressed as

$$
\sigma=\sigma_{0}^{\circ} \dot{R}^{\delta}
$$




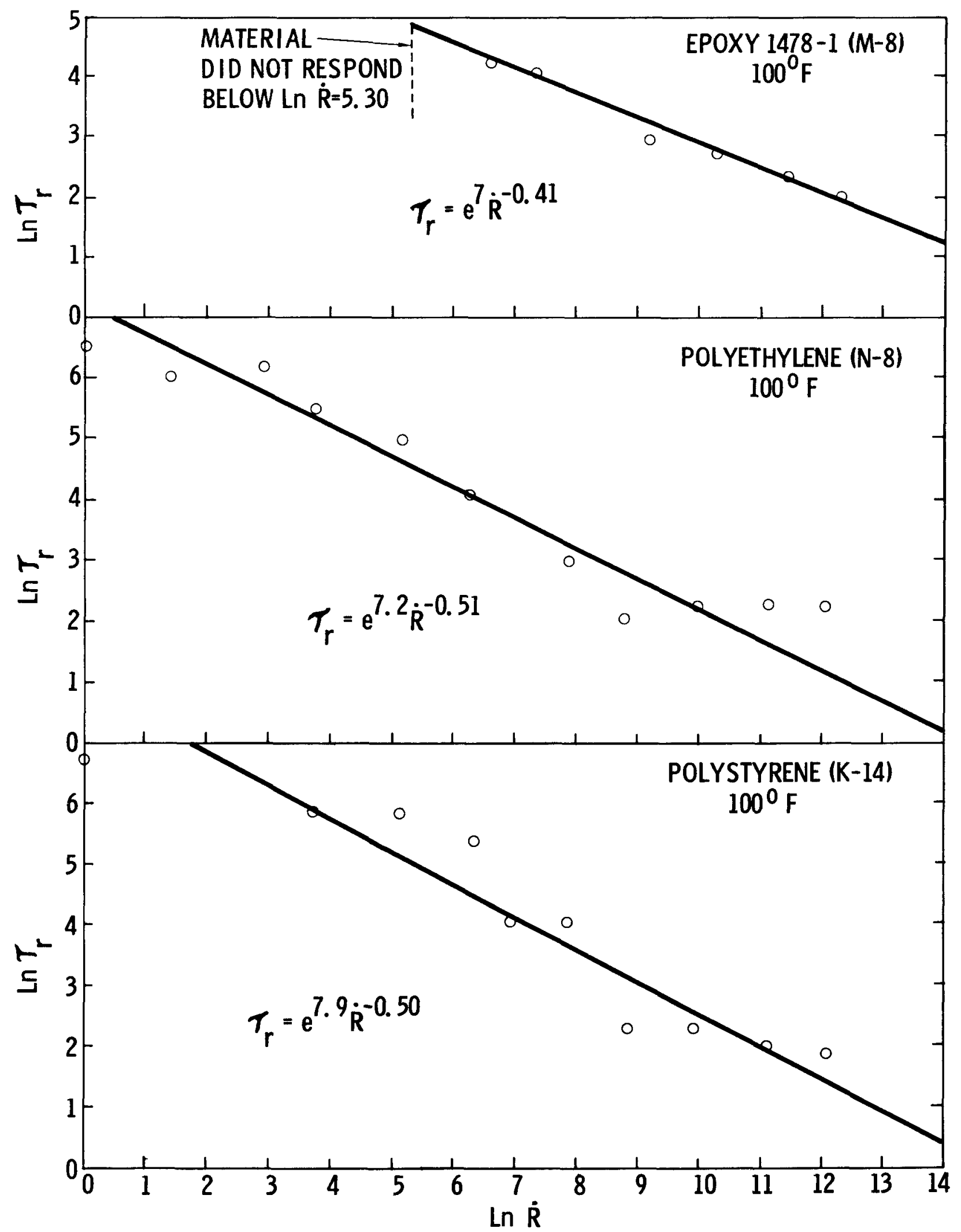

FIG. 4. Ln-Ln PLOT OF RISE TIME, SEC., VERSUS GAMMA-RAY INTENSITY, RADS $\left(H_{2} 0\right) / M I N .$, FOR EPOXY 1478-1, POLYETHYLENE, AND POLYSTYRENE. 


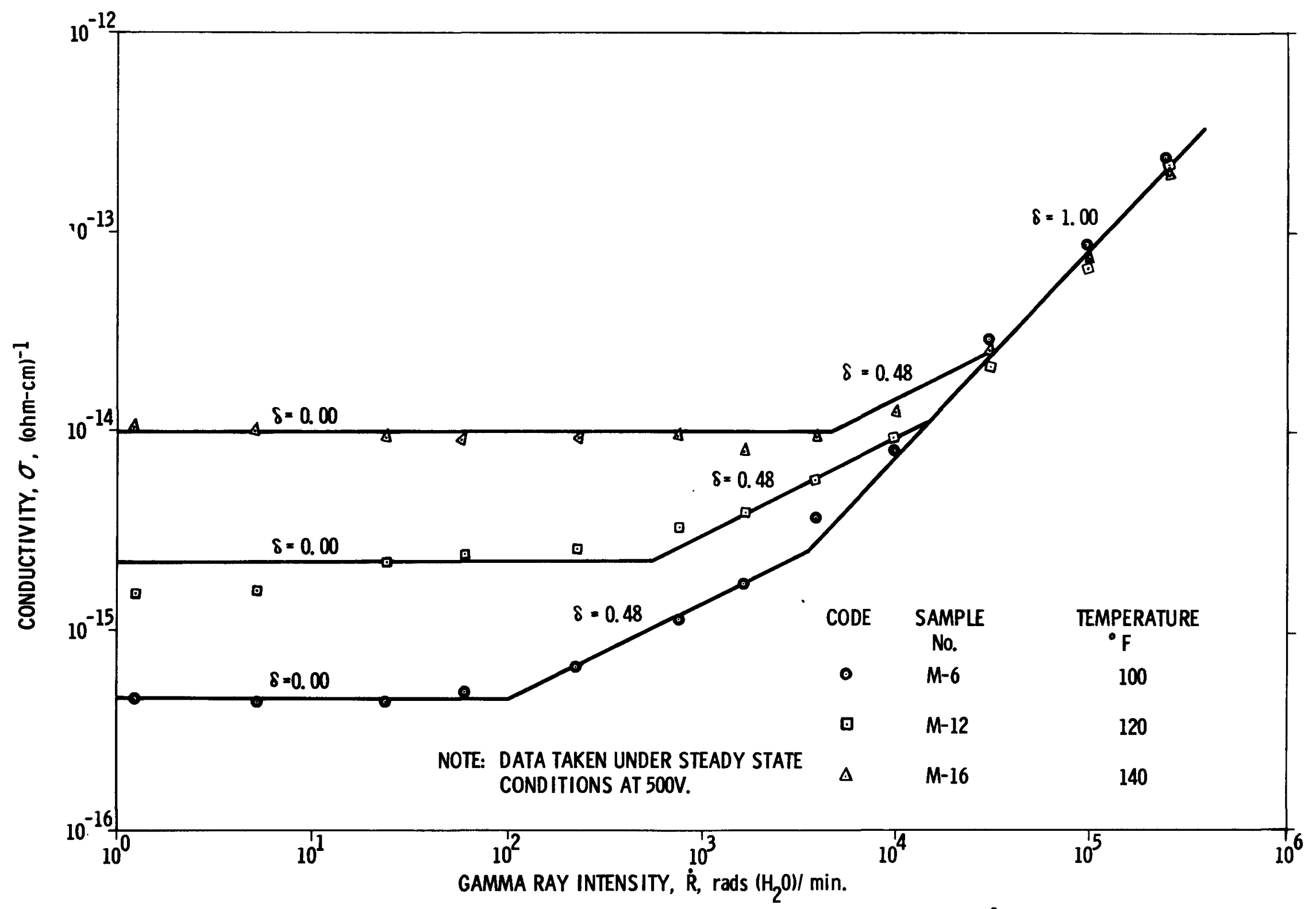

它

FIG. 5. CONDUCTIVITY VERSUS INTENSITY FOR EPOXY 1478-1 AT 100, 120, AND $140^{\circ} \mathrm{F}$. 
where $\dot{R}$ is the gamma-ray intensity in rads $\left(\mathrm{H}_{2} \mathrm{O}\right) / \mathrm{min}$, and $\sigma_{0}^{\circ}$ and $\delta$ are empirical constants. $\sigma_{0}^{\circ}$ and $\delta$ are summarized in Table II with temperature and intensity as variables. A dependence of photoconductivity of this form is expected from the model of Rose $\mathrm{1}^{14}$ and has been previously found by Fowler 15 and by Coleman ${ }^{16}$ at low intensities $\left(\dot{\mathrm{R}}<10^{2}\right.$ rads $\left.\left(\mathrm{H}_{2} \mathrm{O}\right) / \mathrm{min}\right)$. The magnitudes of $\sigma_{0}^{*}$ and $\delta$ measured in this investigation agree, with a few distinct exceptions, with previous results. For example, the nonconstant slope of $\ln \sigma$ versus $\ln \dot{R}$ at higher intensities, as shown in Fig. 5 for Epoxy 1478-1, has not been observed in the intensity range and for the materials included in other reported work. The theoretical treatment of Rose predicts a range of values of $0.50 \leq \delta \leq 1.00$; whereas, values from 0.00 to 2.72 have been measured (Table II). Epoxy 1478-1, Epoxy 1478-3, polyvinylchloride, and nylon exhibit values of $\delta=0.00$ within limited regions of $\dot{R}$. Epoxy 1478-1, polyvinylchloride, and Kel-F exhibit values of $\delta>1.00$ also in limited regions of $\dot{R}$.

A mathematical treatment of the photoconductivity process, with appropriate references, is presented in Appendix F. Based on models by Rose, Fowler has shown how values of $\delta$ between 0.50 and 1.00 might be obtained for insulating materials considering an exponential distribution of trapping levels or a uniform distribution of trapping levels (see Appendix G). For an exponential distribution $(\delta \rightarrow 0.50)$ the traps are considered to be distributed in exponentially decreasing numbers below the conduction band such that the energy distribution is given by

$$
N_{E_{x}} d E_{x}=A e^{-E_{x} / k T_{1} d E_{x}}
$$

where $A$ and $T_{1}$ are constants for a given material and $E_{\mathbf{x}}$ is the photoconductivity activation energy. For a uniform distribution $(\delta \rightarrow 1.00)$ the

${ }^{14}$ Rose, A., op. cit., (Ref. 1).

${ }^{15}$ Fowler, J. A., op. cit., (Ref. 2).

${ }^{16}$ Coleman, J. H., op. cit., (Ref. 3). 
TABLE II

Measured Values of $\delta$ and $\sigma_{0}^{*}$ for Ten Materials as Defined by $\sigma=\sigma_{0}^{*} \dot{R}^{\delta}$

\begin{tabular}{|c|c|c|c|c|c|}
\hline Material & $\begin{array}{c}\text { Sample } \\
\text { No. }\end{array}$ & $\begin{array}{l}\text { Tem- } \\
\text { perature } \\
\left({ }^{\circ} \mathrm{F}\right)\end{array}$ & $\delta$ & $\sigma_{0}^{p}$ & $\begin{array}{c}\text { Range of } \dot{\mathrm{R}}, \\
\left(\operatorname{rads}\left(\mathrm{H}_{2} \mathrm{O}\right) / \mathrm{min}\right)\end{array}$ \\
\hline \multirow[t]{3}{*}{ Polystyrene ${ }^{(1)}$} & $K-20$ & 100 & 0.97 & $7.51 \times 10^{-19}$ & 1.0 to $3.0 \times 10^{5}$ \\
\hline & $\mathrm{K}-18$ & 120 & 0.97 & $7.51 \times 10^{-19}$ & 1.0 to $3.0 \times 10^{5}$ \\
\hline & $\mathrm{K}-19$ & 140 & 0.97 & $7.51 \times 10^{-19}$ & 1.0 to $3.0 \times 10^{5}$ \\
\hline \multirow[t]{3}{*}{ Polyethylene ${ }^{(1)}$} & $\mathrm{N}-3$ & 100 & 0.74 & $2.52 \times 10^{-17}$ & 5.0 to $1.0 \times 10^{5}$ \\
\hline & $\mathrm{N}-12$ & 120 & 0.74 & $3.05 \times 10^{-17}$ & 5.0 to $1.0 \times 10^{5}$ \\
\hline & $\mathrm{N}-7$ & 140 & 0.73 & $7.56 \times 10^{-17}$ & 5.0 to $1.0 \times 10^{5}$ \\
\hline \multirow[t]{9}{*}{ Epoxy 1478-1 (1) } & $M-6$ & 100 & 0.00 & $4.57 \times 10^{-16}$ & 1.0 to $1.0 \times 10^{2}$ \\
\hline & & & 0.48 & $5.08 \times 10^{-17}$ & $1.0 \times 10^{2}$ to $3.5 \times 10^{3}$ \\
\hline & $\vdots$ & & 1.00 & $5.56 \times 10^{-19}$ & $3.5 \times 10^{3}$ to $2.5 \times 10^{5}$ \\
\hline & $M-12$ & 120 & 0.00 & $2.26 \times 10^{-15}$ & 1.0 to $5.4 \times 10^{2}$ \\
\hline & & & 0.48 & $1.13 \times 10^{-16}$ & $5.4 \times 10^{2}$ to $1.5 \times 10^{4}$ \\
\hline & ! & & 1.00 & $5.56 \times 10^{-19}$ & $1.5 \times 10^{4}$ to $2.5 \times 10^{5}$ \\
\hline & $M-16$ & 140 & 0.00 & $1.01 \times 10^{-14}$ & 1.0 to $4.5 \times 10^{3}$ \\
\hline & & & 0.48 & $1.69 \times 10^{-16}$ & $4.5 \times 10^{3}$ to $3.3 \times 10^{4}$ \\
\hline & & & 1.00 & $5.56 \times 10^{-19}$ & $3.3 \times 10^{4}$ to $2.5 \times 10^{5}$ \\
\hline \multirow[t]{2}{*}{ Epoxy $1478-3^{(2)}$} & $\mathrm{C}-2$ & 90 & 0.00 & $1.66 \times 10^{-15}$ & $1.0 \times 10^{1}$ to $1.4 \times 10^{3}$ \\
\hline & & & 0.94 & $2.04 \times 10^{-18}$ & $1.4 \times 10^{3}$ to $5.3 \times 10^{4}$ \\
\hline \multirow{3}{*}{$\begin{array}{l}\text { Epoxy } 1478-22^{(2)} \\
\text { Polyvinylchloride }\end{array}$} & $\mathrm{B}-2$ & 90 & 1.00 & $1.51 \times 10^{-18}$ & $1.0 \times 10^{1}$ to $5.3 \times 10^{4}$ \\
\hline & $e^{(2)} 1-1$ & 90 & 0.00 & $1.37 \times 10^{-17}$ & $1.0 \times 10^{1}$ to $1.3 \times 10^{3}$ \\
\hline & & & 2.72 & $5.62 \times 10^{-26}$ & $1.3 \times 10^{3}$ to $5.3 \times 10^{4}$ \\
\hline
\end{tabular}


TABLE II (continued)

\begin{tabular}{|c|c|c|c|c|c|}
\hline Material & $\begin{array}{l}\text { Sample } \\
\text { No. }\end{array}$ & $\begin{array}{l}\text { Tem- } \\
\text { perature } \\
\left({ }^{\circ} \mathrm{F}\right)\end{array}$ & $\delta$ & $\sigma_{0}^{\circ}$ & $\begin{array}{c}\text { Range of } \dot{R}, \\
\left.\text { (rads }\left(\mathrm{H}_{2} \mathrm{O}\right) / \mathrm{min}\right)\end{array}$ \\
\hline Polypropylene ${ }^{(2)}$ & $A-3$ & 90 & $\begin{array}{l}0.82 \\
-.(3) \\
0.99\end{array}$ & $\begin{array}{l}1.51 \times 10^{-18} \\
-(3) \\
1.51 \times 10^{-18}\end{array}$ & $\begin{array}{l}1.0 \times 10^{1} \text { to } 3.7 \times 10^{2} \\
3.7 \times 10^{2} \text { to } 9.0 \times 10^{2} \\
9.0 \times 10^{2} \text { to } 5.3 \times 10^{4}\end{array}$ \\
\hline Teflon ${ }^{(2)}$ & $D-1$ & 90 & 0.78 & $1.69 \times 10^{-17}$ & $1.0 \times 10^{1}$ to $5.3 \times 10^{4}$ \\
\hline Nylon (2) & $F-1$ & 90 & $\begin{array}{l}0.00 \\
0.68\end{array}$ & $\begin{array}{l}2.26 \times 10^{-14} \\
4.57 \times 10^{-17}\end{array}$ & $\begin{array}{l}1.0 \times 10^{1} \text { to } 1.9 \times 10^{4} \\
1.9 \times 10^{4} \text { to } 5.3 \times 10^{4}\end{array}$ \\
\hline $\mathrm{Kel}-\mathrm{F}^{(2)}$ & G-2 & 90 & $\begin{array}{l}0.44 \\
2.00\end{array}$ & $\begin{array}{l}1.85 \times 10^{-18} \\
2.05 \times 10^{-23}\end{array}$ & $\begin{array}{l}1.0 \times 10^{1} \text { to } 1.5 \times 10^{3} \\
1.5 \times 10^{3} \text { to } 5.3 \times 10^{4}\end{array}$ \\
\hline
\end{tabular}

(1) Data taken under steady-state conditions at $500 \mathrm{v}$.

(2) Data taken at $500 \mathrm{v}$ after 60 seconds of electrification.

(3) The relationship $\sigma=\sigma_{0}^{0} \dot{\mathrm{R}}^{\delta}$ will not hold in this region.

Note: $\sigma$ has units of $\mathrm{ohm}^{-1} \mathrm{~cm}^{-1}$ and $\dot{\mathrm{R}}$ has units of rads $\left(\mathrm{H}_{2} \mathrm{O}\right) / \mathrm{min}$. 
traps are considered to be distributed uniformly in energy below the conduction band such that

$$
\mathrm{N}_{\mathrm{E}_{x}} \mathrm{dE}_{x}=\text { Constant } \mathrm{dE} \mathrm{E}_{x}
$$

For some of the materials in Table II the photoconductivity varies with a power of photon intensity greater than unity. This phenomenon is commonly called "superlinear photoconductivity." According to Rose," ${ }^{17}$ superlinearity will occur when the hole demarcation level, * the energy level of which is associated with the location of the electron Fermi level, moves down to include a class of defect centers as recombination centers that have small recombination cross sections. Superlinear photoconductivity is not uncommon and has been measured and reported by Bube ${ }^{18}$ in cadmium selenide (CdSe) and cadmium sulfide (CdS).

The conductivity values $(\sigma)$ presented in this thesis include both the dark conductivity $\left(\sigma_{\mathrm{o}}\right)$ and photoconductivity $\left(\sigma_{\mathrm{p}}\right)$, i. e.,

$$
\sigma=\sigma_{0}+\sigma_{\mathrm{p}}=\sigma_{0}^{\cdot} \dot{\mathrm{R}}^{\delta}
$$

In most cases the photoconductivity completely masks the dark conductivity and

$$
\sigma=\sigma_{0}^{\circ} \dot{R}^{\delta} \approx \sigma_{\mathrm{p}}
$$

There are exceptions to Eq. 8 where the dark conductivity completely masks the photoconductivity and within the accuracy of the instrumentation no photoconductivity is measured, i.e.,

$$
\sigma=\sigma_{0}^{\cdot} \dot{R}^{\delta} \approx \sigma_{0}
$$

In such instances (see Table II) $\delta$ is considered to be zero and Eq. 7 reduces to

$$
\sigma=\sigma_{0}^{*} \approx \sigma_{0}
$$

17Rose, A. , "Recombination Processes in Insulators and Semiconductors," Phys. Rev., 97, 322 (1955).

*Hole demarcation level - defined as the energy level separating hole trapping and hole recombination levels in the band structure.

${ }^{18}$ Bube, R. H., "Photoconductivity of the Sulfide, Selenide, and Telluride of Zinc or Cadmium," IRE Trans., $\underline{43}$ (2), 1836, December (1953). 
In all of this work "volume excited currents" are assumed, i.e., free positive and negative charges are equally distributed and space charge effects do not enter in. The rate of generation of these free positive and negative charges is a function of the gamma-ray intensity, and Appendix $\mathrm{H}$ presents and discusses a functional relationship for this generation rate, based on a best estimate of the average energy required for each hole-electron pair formed.

\section{Conductivity Versus Temperature}

Conductivity has been measured to vary with temperature under both dark and photoinduced conductivity conditions according to the general relationship

$$
\sigma=\sigma_{0} e^{-E / k T}
$$

where $E=E_{o}$, the thermal activation energy for dark conductivity, or $E=E_{\mathbf{x}}$, the thermal activation energy for photoconductivity. Values of $\mathrm{E}_{\mathbf{0}}$ and $\mathrm{E}_{\mathbf{x}}$ for polyethylene, polystyrene, and Epoxy 1478-1 are presented in Table III. The thermal activation energy is lowered by irradiation except, as is noted, for the epoxy formulation in Region 1 where $E_{0}=E_{\mathbf{x}} \cdot E_{\mathbf{x}}$ for the epoxy is zero in Region 3 which indicates that the photoconductivity is independent of temperature. Figures A-1, A-2, and A-3 of Appendix A represent conductivity versus (absolute temperature) ${ }^{-1}$ data for Epoxy 1478-1, polyethylene, and polystyrene, respectively.

TABLE III

Thermal Activation Energies and Photoconductivity Activation Energies

\begin{tabular}{|c|c|c|}
\hline Material & $\begin{array}{c}\text { Thermal activation energy, } \\
\mathrm{E}_{\mathrm{O}}, \\
\mathrm{ev}\end{array}$ & $\begin{array}{c}\text { Photoconductivity } \\
\text { activation energy, } \\
\mathrm{E}_{\mathbf{x}} \\
\mathrm{ev}^{\prime}\end{array}$ \\
\hline Polyethylene & 0.52 & 0.40 \\
\hline Polystyrene & 0.50 & 0.13 \\
\hline Epoxy 1478-1 & 1.19 & \\
\hline Region 1 & & 1.19 \\
\hline Region 2 & & 0.48 \\
\hline Region 3 & & 0.00 \\
\hline
\end{tabular}


Conductivity Versus Accumulated Exposure

In addition to the gamma-ray photoconductivity effects in these insulating materials, a dark conductivity increase is sometimes measured after a given accumulated exposure, R. Figure 6 summarized such data for ten materials. These conductivities were measured 24 hours after exposure. Except for polyethylene and polystyrene, no extremely large changes are measured to $10^{6}$ rads $\left(\mathrm{H}_{2} \mathrm{O}\right)$. However, Teflon is beginning to show an upward trend, whereas polypropylene shows a distinct conductivity decrease.

\section{Conductivity Recovery}

Conductivity decays slowly after abruptly stopping radiation exposure. This slow rate of decay is assumed to be dictated by the effect of trapping. The effect of trapping is to make the measured decay time constant* of the photoconductivity longer than the carrier decay rate. In the absence of trapping centers, the measured photoconductivity decay will be equal to the recombination of the free carriers. If a discreet number of trapping centers is present, but the free carrier density is much greater than the trapped carrier density, then the observed initial decay of the photocurrent will again be the recombination rate of free carriers. When the density of free carriers is comparable to or less than the density of trapped carriers, the thermal freeing of trapped carriers during the decay process will prolong the decay so that the observed decay time constant is longer than the actual recombination rate. In the extreme case where the density of trapped carriers is much greater than the density of free carriers, the photoconductivity decay is effectively dominated by the rate of trap decay.

The measured photoconductivity decay for the organic materials of this work can be characterized as in Eq. 12

$$
\sigma(t)=\sigma_{\text {eq }}\left[A e^{-t / \tau_{1}}+B e^{-t / \tau_{2}}\right]
$$

by one or two time constants, $\boldsymbol{\tau}_{1}$ and $\boldsymbol{\tau}_{2}$, where $A$ and $B$ are weighting factors. Decay data for polyethylene, polystyrene, and Epoxy 1478-1 after

*Decay time constant - time required for the conductivity to decay to $1 / \mathrm{e}$ its initial value. 


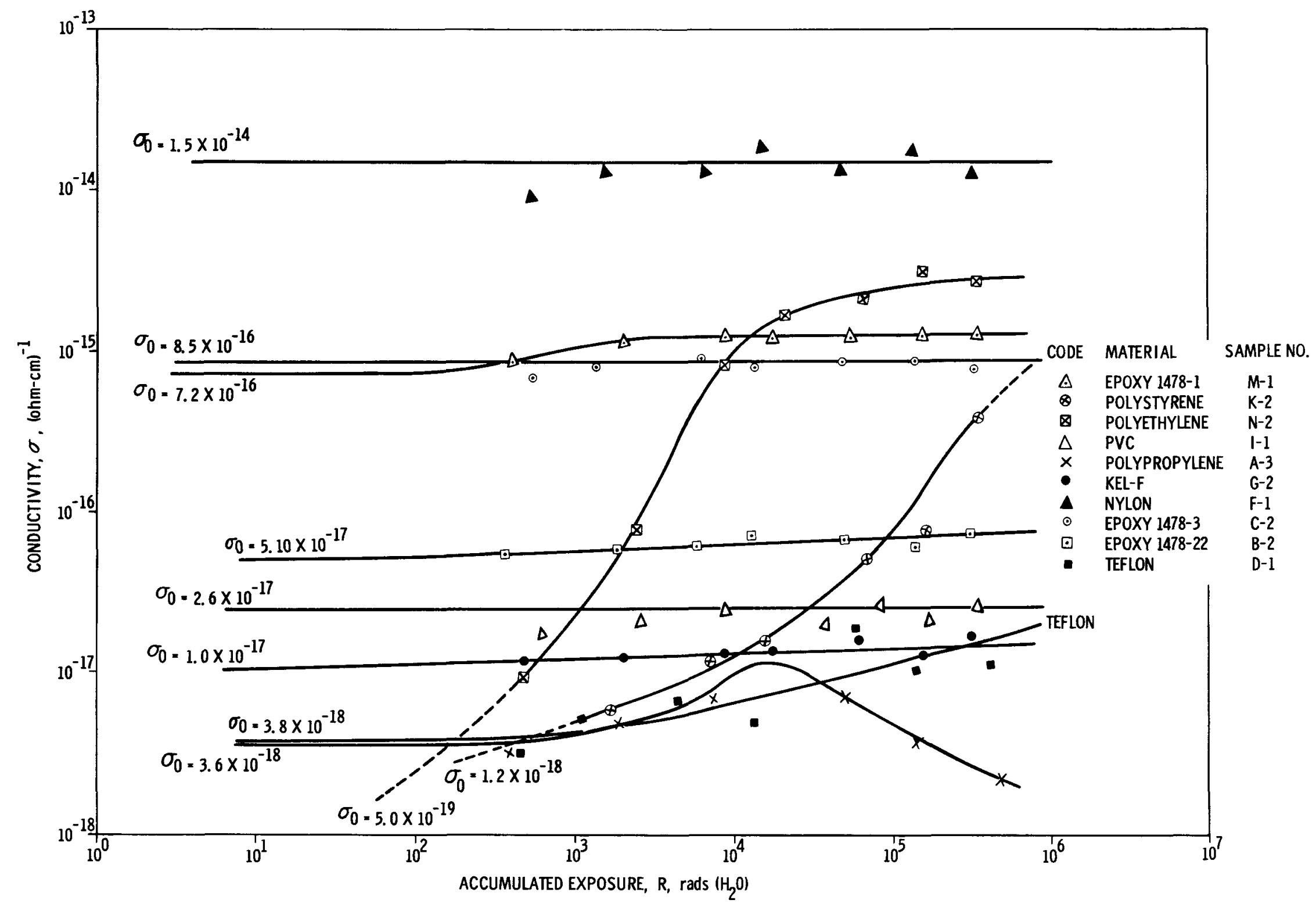

FIG. 6. CONDUCTIVITY VERSUS ACCUMULATED EXPOSURE FOR TEN MATERIALS MEASURED 24 HOURS AFTER EACH EXPOSURE, AT 500 V., AFTER 60 SEC. OF ELECTRIFICATION, AND AT $90^{\circ} \mathrm{F}$. 
exposure to $2.0 \times 10^{5} \mathrm{rads}\left(\mathrm{H}_{2} \mathrm{O}\right) / \mathrm{min}$ at $130^{\circ} \mathrm{F}$ are presented in Fig.7. For polystyrene, $\tau_{1}=2$ seconds and $\tau_{2}=20$ seconds. For Epoxy 1478-1, $\tau_{1}=$ 2.2 seconds and $\tau_{2}$, if indeed it exists, is very long. In comparison, polyethylene has much longer time constants, and the shape of the decay curve does not permit the separation of these constants. Other measured data which support the existence of long decay time constants are presented in Fig. 8. This figure shows ascending and descending curves of photoconductivity for polyethylene, polystyrene, and Epoxy $1478-1$ as a function of intensity with time allowed for conductivity stabilization at each plateau. Epoxy 1478-1 repeats a descent; polystyrene on descent departs from the ascending curve at a low intensity; and polyethylene on descent departs immediately from the ascending curve. 


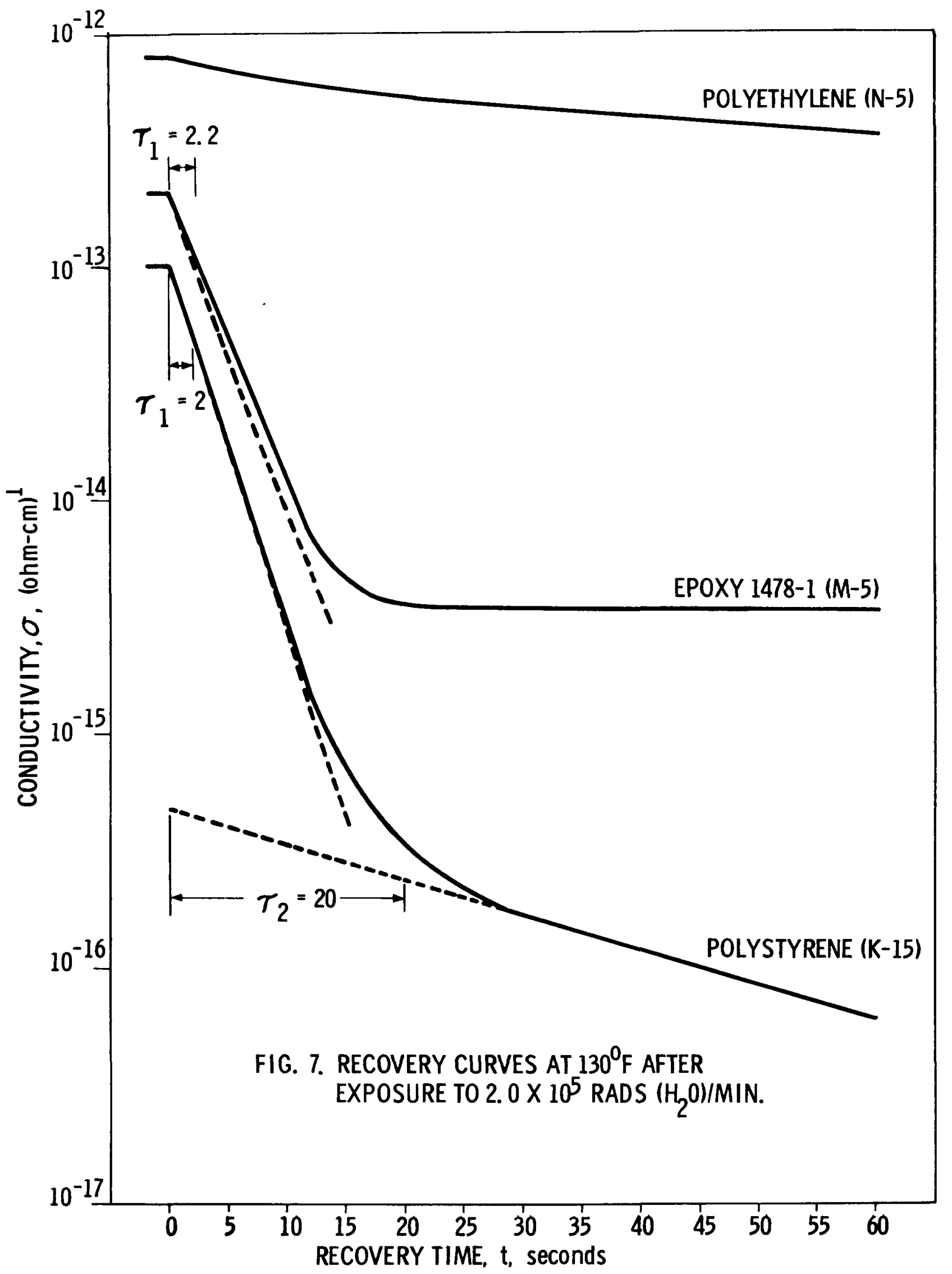




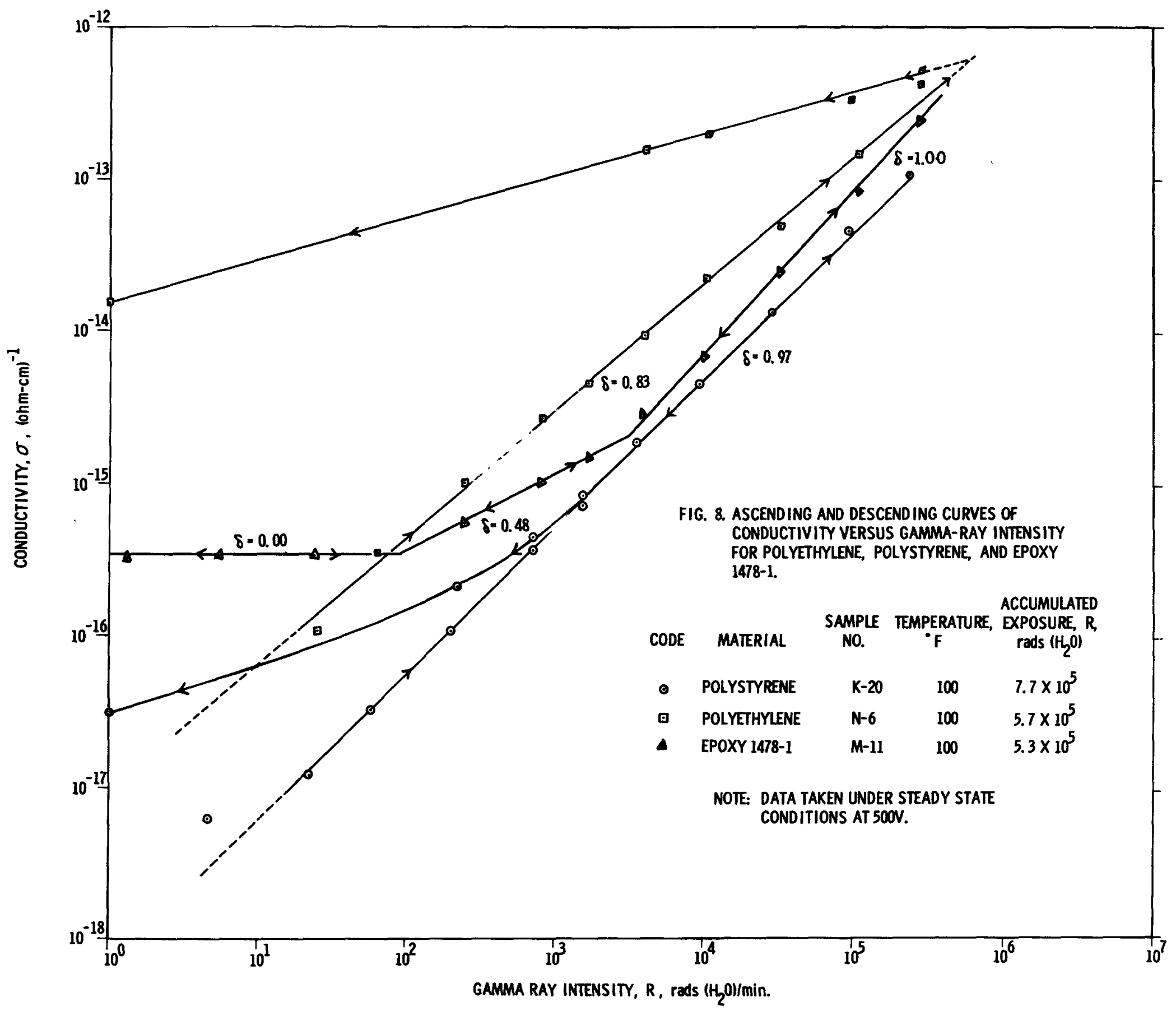

ज̃ 


\section{CHAPTER IV -- SUMMARY}

This study of gamma-ray photoconductivity in organic dielectric materials has resulted in four distinct observations. The first measured phenomenon shows that the time required for the photoconductivity to achieve equilibrium upon exposure to a step increase in gamma-ray intensity $(\mathrm{R})$--denoted as rise time, $\boldsymbol{\tau}_{\mathbf{r}}$--to be inversely proportional to intensity, and the functional relationship characterizing this measured behavior is $\tau_{\mathbf{r}}=\tau_{\mathbf{r}}^{\prime} \hat{R}^{-\mu}$. Secondly, a dependence of photoconductivity on irradiation intensity at a given temperature in all insulating materials studied was measured to be characterized to good approximation in one or more regions of $\dot{R}$, within which conductivity is expressed as $\sigma=\sigma_{0}^{\&} \dot{R}^{\delta}$. The third observation concerns the conductivity decay upon removal of the sample from the gamma-ray environment. This decay was measured to be characterized by one or two decay constants, $\tau_{1}$ and $\tau_{2}$, and is approximated by the relationship

$$
\sigma(t)=\sigma_{e q}\left[A e^{-t / \tau_{1}}+B e^{-t / \tau_{2}}\right] .
$$

The fourth observation shows that the conductivity was measured to vary with temperature under both dark and induced conductivity conditions according to the relationship $\sigma=\sigma_{0} \mathrm{e}^{-\mathrm{E} / \mathrm{K} \mathbf{T}}$

With the above qualitative information in hand, it is desirable to concentrate future experimental efforts toward the accumulation of knowledge as to the type and mobility of the carriers contributing to photoconductivity and toward a qualitative understanding of the distribution of states in the "band gap, " all of which is needed for a better understanding of the mechanism of photoconductivity in organic dielectrics. 


\section{BIBLIOGRAPHY}

Aftergut, S. A., and Brown, G. P., Electronic Properties of Organic Compounds, General Electric Co., Schenectady, New York. Paper given at Conference on Organic Semiconductors, Chicago, April 18-19, 1961.

Birks, J. B., and Schulman, J. H., Progress in Dielectrics, Heywood and Company, Ltd., 1960, Vol. 2.

Bovey, F. A., The Effects of Ionizing Radiation on Natural and Synthetic High Polymers, Interscience Publishers, Inc., New York, 1958, Vol. 1.

Bube, R. H., "Mechanism of Photoconductivity in Microcrystalline Powder," JAP, 31, (12), 2239-2254 (1960).

Bube, R. H., Photoconductivity of Solids, John Wiley and Sons, Inc., New York, 1960.

Bube, R. H., "Photoconductivity of the Sulfide, Selenide, and Telluride of Zinc or Cadmium, "IRE, 느, (2), 1836-1850 (1955).

Charlesby, A., Atomic Radiation and Polymers, Pergamon Press, New York, 1960.

Clayton, C. G., and Haywood, B. C., "Conductivity Induced by Radiation in Polycrystalline Cadmium Sulfide and Polyethylene, " Nature, 183, 1112-1113, April (1959).

Coleman, J. H., 23rd Annual Meeting, Conference on Electrical Insulation, Sponsored by National Academy of Science-National Research Council, 1955.

Fowler, J. F., "X-Ray Induced Conductivity in Insulating Materials," Proceedings of the Royal Society of London, 464 (1956). 
Frederikse, H. P. R., and Blunt, R. F., "Photoeffects in Intermetallic Compounds," IRE, 43, (2), 1828-1835 (1955).

Fujiwara, S., et. al., "Nuclear Magnetic Resonance in Irradiated Polyethylene, " Journal of Chemical Physics, 26, (5), 1343 (1957).

Goldstein, H., and Wilkins, J. E., Jr., Nuclear Development Associates, Inc., NYO-3075, June 30, 1954.

Goodman, J., and Coleman, J. H., The Dose Rate Dependence of Kel-F Degradation by Ionizing Radiation, Radiation Research Corp., 140 East 59 th St., N. Y., 22, N. Y.

Gudden, B., and Pohl, R., "Photoelectric Conductivity," Phys. Zeits., 23, $417(1922)$.

Hermann, F., "The Electronic Energy Band Structure of Silicon and Germanium, "IRE, 43, (2), 1703-1732 (1953).

Jaynes, E. T., "Nonlinear Dielectric Materials," IRE, 43, (2), 1733-1737 (1955).

Kallman, H., et. al., "Calculation of the Photoconductivity from A. C. Impedance Charges Induced in $\mathrm{ZnS}$ and $\mathrm{ZnCdS}$ Phosphors, "Journal Physics and Chemistry Solids, 10, 57-63 (1959).

Kittel, C., Introduction to Solid State Physics, John Wiley and Sons, Inc., New York, 1957.

Lampert, M. A., and Rose, A., "Transient Behavior of the Ohmic Contact," Phys. Rev., 113, (5), 1236-1239 (1959).

Lauritzen, J. I., and Hoffman, J. D., "Theory of Formation of Polymer Crystals with Folded Chains in Dilute Solutions, " J. Res., N.B.S., 64A, 73 (1960). 
Lee, Henry, and Neville, Kris, Epoxy Resins, McGraw-Hill Book Co., Inc. , 1957.

Loebner, E. E., "Opto-Electric Devices and Networks," IRE, 43, (2), 1897-1906 (1955).

Michel, A. E., "Photoconductivity of Silver Chloride Crystals Under Pulsed X-Ray Irradiation, " Phys. Rev., 121, (4), 968-977 (1961).

Moss, T. S., Photoconductivity in the Elements, Butterworths Scientific Publications, London, 1952.

Moss, T. S., "Lead Salt Photoconductors, " IRE, 43, (2), 1869-1881 (1955).

Photoconductivity Conference, John Wiley and Sons, Inc., 1956.

Price, W. J., Nuclear Radiation Detection, McGraw-Hill Book Co., Inc., 1958.

Rittner, E. S., "Electron Processes in Photoconductors," Photoconductivity Conference, Atlantic City, 1954.

Rose, A., and Lampert, M. A., "Gain-Bandwidth Product for Photoconductors," RCA Review, 57-68, March (1959).

Rose, A., and Lampert, M. A., "Photoconductor Performance, Space Charge Currents, and the Steady State Fermi Level, "Phys. Rev., 113, (5) 1227-1235 (1959).

Rose, A., "An Outline of Some Photoconductive Processes, " RCA Review, 12 , 362 (1951).

Rose, A., "Performance of Photoconductors, " IRE, 43, (2) 1850-1869 (1955). 
Rose, A., "Recombination Processes in Insulators and Semiconductors," Phys. Rev., 97, 322 (1955).

Schultz, M. L., and Morton, G. A., "Photoconduction in Germanium and Silicon, "IRE, $\underline{43}$, (2), 1819-1828 (1955).

Seitz, F., and Koehler, J. S., International Conference on Peaceful Uses of Atomic Energy, Geneva, 7, 615 (1955).

Sheist, Irving, Epoxy.Resins, Reinhold Publishing Co., New York, 1959.

Shockley, W., Electrons and Holes in Semiconductors, Van Norstrand Co., Inc., New York, 1959.

Simha, R., and Wall, L. A., "Mechanism of High Energy Radiation Effects in Polymers," Journal of Physical Chemistry, 61, (4), 420-430, April (1957).

Smith, W., "Effects of Light on Selenium During the Passage of an Electric Current, " Nature, 7, 303 (1873).

Smyth, C. P., Dielectric Behavior and Structure, McGraw-Hill Book Co., Inc., New York, 1955.

Sproull, R. L., Modern Physics, John Wiley and Sons, Inc., New York, 1956.

von Hippel, A. R., (Editor), Dielectric Materials and Applications, John Wiley and Sons, Inc., New York, 1954.

Whitehead, S., Dielectric Breakdown of Solids, Oxford at the Clarendon Press, 1953. 


\section{APPENDIX A}

\section{MECHANISMS OF GAMMA-RAY INTERACTION WITH MATTER}

There are three principal mechanisms by which gamma rays interact with matter to produce photoconductivity phenomena. These mechanisms are photoelectric effect, Compton effect, and pair production. These topics are discussed extensively in many texts. Five such texts are referenced here. ${ }^{19-23}$

In the photoelectric effect, high-energy photons interact with the orbital electrons of the material. All of the photon energy is absorbed and the electron is ejected with an energy equal to that of the incident photon less the binding energy of the electron, i. e.,

$$
E_{k}=h \nu-\omega
$$

where $E_{k}$ is the kinetic energy of the emitted electron, $h$ is the Planck constant, $\nu$ is the frequency of the radiation, and $\omega$ is the energy necessary to eject the electron.

${ }^{19}$ Charlesby, A. , Atomic Radiation and Polymers, Pergamon Press, New York, 1960.

${ }^{20}$ Bovey, F. A., The Effects of Ionizing Radiation on Natural and Synthetic High Polymers, Interscience Publishers, Inc., New York, 1958, Vol. 1, Ch.1, p. 16 . 1956.

${ }^{21}$ Sproull, R. L., Modern Physics, John Wiley and Sons, Inc., New York,

${ }^{22}$ Birks, J. B., and Schulman, J. H., Progress in Dielectrics, Heywood and Company, Ltd., 1960, Vol. 2, p. 85.

${ }^{23}$ Price, W. J., Nuclear Radiation Detection, McGraw-Hill Book Co., Inc., 1958. 
The Compton effect is an elastic collision, to the first approximation, between a gamma-ray photon and an electron. Energy, which is sufficient to eject the latter with considerable velocity, is transferred. Compton electrons then lose their energy, as in the photoelectric effect, mainly by excitation and ionization of other atoms and may have initial energies ranging from 0 to a fraction,

$$
\frac{2 h \nu}{m_{\circ} c^{2}+2 h \nu}
$$

of that of the incident photon. The quantity $h \nu$ is the energy of the incident photon and $\mathrm{m}_{\mathrm{o}} \mathrm{c}^{2}$ is the rest energy of the electron. For gamma-ray photoconductivity work in organic polymers, Compton effect is more pronounced than either photoelectric absorption or pair production. This is exemplified in Fig. A-1 where mass absorption coefficient* versus photon energy for carbon, the prime constituent of the polymer materials studied here, is presented. (These data taken from Bovey, Ref. 24.)

Electron-position (pair) production results when the energy of an incident photon is greater than twice the rest energy of an electron $\left(2 \mathrm{~m}_{0} \mathrm{c}^{2} \times\right.$ 1. $02 \mathrm{Mev})$. The photon (h $\nu$ ) interacts with the field of the nucleus to produce a positive and a negative electron. The excess energy $\left(E_{k}\right)$

$$
E_{k}=h \nu-2 m_{o} c^{2}
$$

then appears as the sum of the kinetic energies of the electron and positron. The positron has a short life and eventually combines with an electron to give two photons.

* The mass absorption coefficient $(\mu)$ of an element is the fractional decrease in intensity per unit surface density.

24 Bovey, F. A., op cit., (Ref. 20, p. 20 ). 


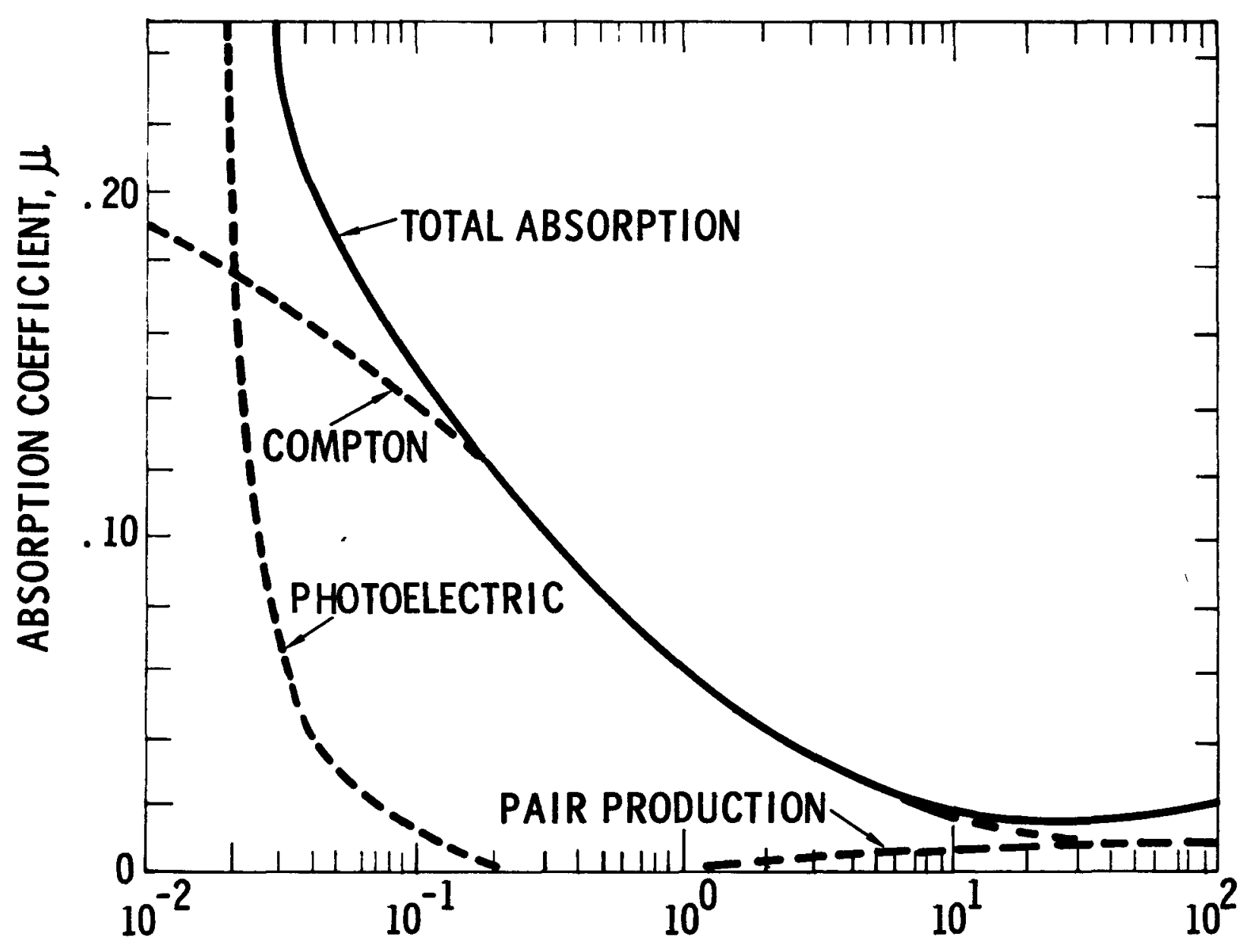

PHOTON ENERGY IN MEV

FIG. A-1. ABSORPTION COEFFICIENT VERSUS PHOTON ENERGY FOR CARBON. 


\section{APPENDIX B}

\section{TYPICAL ELECTRON TRANSITIONS IN PHOTOCONDUCTORS}

The photoconductivity phenomenon is a consequence of the absorption of energy from electromagnetic radiation in a given material. This absorbed energy produces ionization and excitation by the three methods described in Appendix A. The more common electron transitions ${ }^{25}$ which occur in the photoconductivity process are presented in Fig. B-1. Transition: (1) represents photon absorption by the atoms of the material producing a free electron and a free hole; (2) represents photon absorption at localized imperfections producing a free electron and a hole bound in the neighborhood of the imperfection; (3) represents photon absorption, raising an electron from the valence band to an unoccupied imperfection level, producing a free hole and an electron bound in the neighborhood of the imperfection; (4) represents trapping and thermal release of holes in hole traps (electron transition); (5) represents trapping and thermal release of electrons in electron traps; (6) represents recombination where a free electron combines directly with a free hole; (7) represents recombination through recombination centers where a hole is captured by an excited center containing an electron; and (8) represents recombination through recombination centers where an electron is captured by an excited center containing a hole.

25 Bube, R. H., op. cit., (Ref. 11, Ch.2, p. 10). 


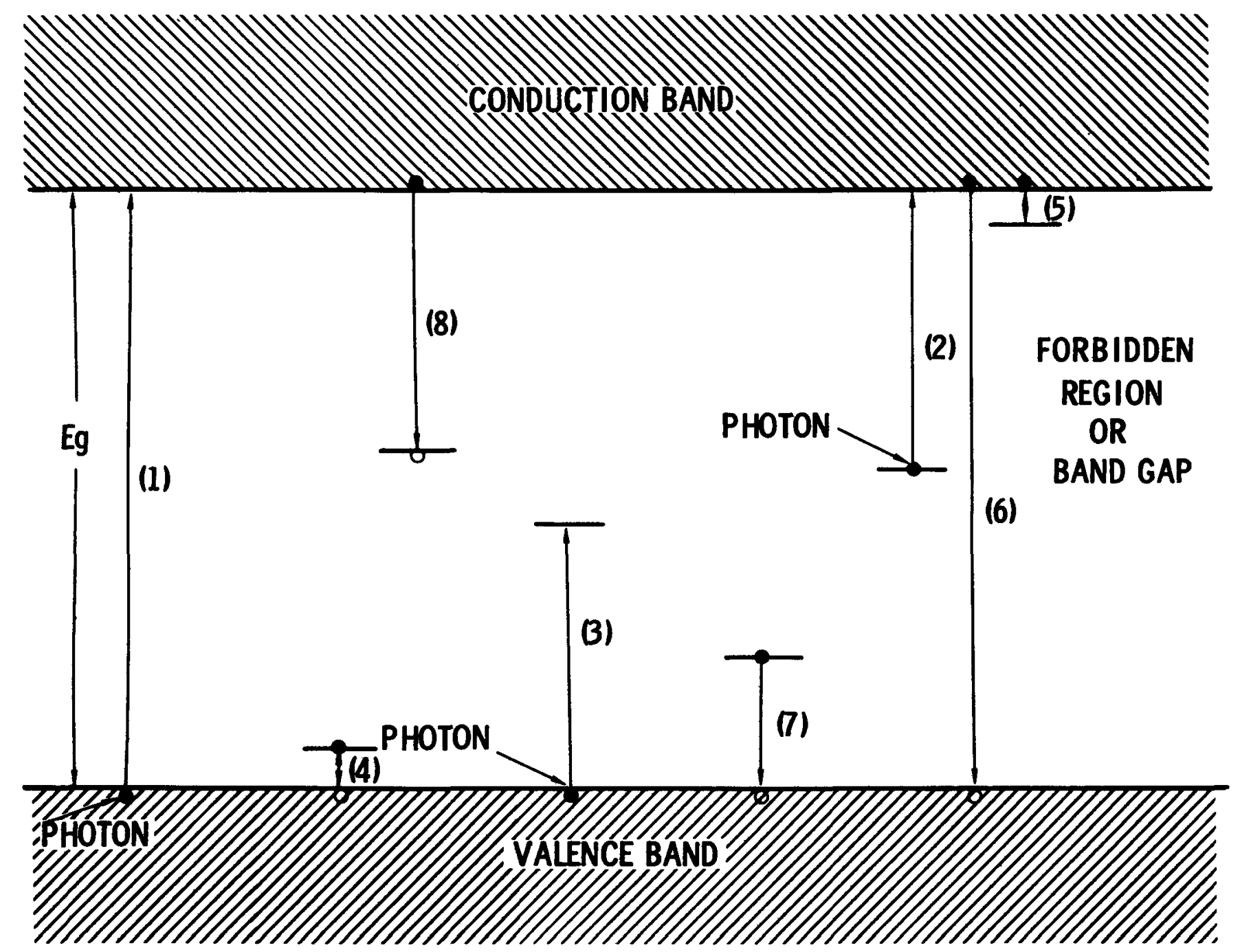

FIG. B-1. COMMON ELECTRON TRANSISTIONS IN PHOTOCONDUCTORS. 


\section{APPENDIX C}

CHEMICAL STRUCTURE OF SELECTED ORGANIC MATERIALS ${ }^{26-28}$

This appendix is included to present a brief description of the molecular structure of those materials studied in this photoconductivity work. The thermalplastics discussed are polyethylene, polystyrene, polypropylene, nylon, Teflon, polyvinylchloride, and Kel-F. The three thermalsetting Epoxy formulations discussed are 1478-1, 1478-3, and 1478-22.

Polyethylene

The polyethylene (Marlex 50) polymer is reported to be as high as 60 percent crystalline. This is a linear polymer and is typically represented as

$$
\left[-\mathrm{CH}_{2}-\mathrm{CH}_{2}-\right]_{\mathrm{n}}
$$

specific gravity 0.96

Polystyrene

Polystyrene has a long chain structure with a benzene ring attached as indicated below:

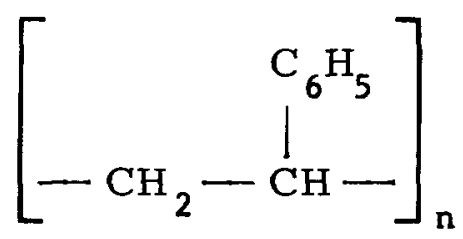

specific gravity 1.02

All presently available polystyrene is completely amorphous due to the random stereoisomerism of the structure.

26 Birks, J. B., and Schulman, J. H., op. cit., (Ref. 22, pp. 29-77). 27 Sheist, Irving, Epoxy Resins, Reinhold Publishing Corp., New York, 1959.

${ }^{28}$ Lee, Henry, and Neville, Kris, Epoxy Resins, McGraw-Hill Book Co., Inc., 1957. 


\section{Polypropylene}

The basic propylene structure is<smiles>C/C=C\C</smiles>

Propylene does not polymerize readily. The polypropylene molecule can exist as an atactic (random) polymer, isotactic (all the substituents lie on one side of a theoretical plane containing the main $\mathrm{C}-\mathrm{C}$ chain) polymer, or syndiatactic (the substituents alternate above and below a theoretical plane containing the main $\mathrm{C}-\mathrm{C}$ chain) polymer. Here the polypropylene molecule is represented as a syndiatactic polymer.

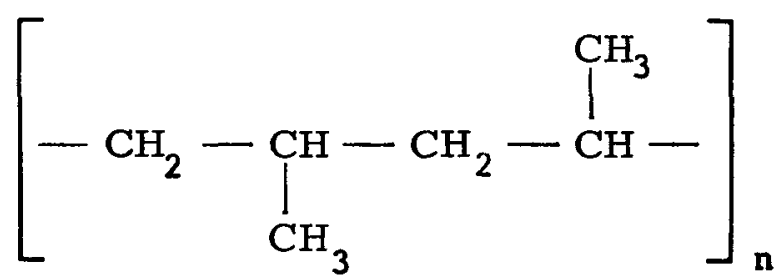

specific gravity 0.91

Nylon

The nylon used here was Zitol 101 (66 nylon) and is formed from the six-carbon acid and six-carbon diamine, adipic acjd, and hexamethylene. diamine. The structure is as follows:

$$
\mathrm{HO}\left[{\mathrm{OC}\left(\mathrm{CH}_{2}\right)_{4}}^{\mathrm{C}}-\left.\right|_{\text {Polytetrafluoroethylene (Teflon) }} ^{\mathrm{O}}-\left(\mathrm{CH}_{2}\right)_{6}-\mathrm{NH}-\right]_{\mathrm{n}} \mathrm{H}
$$

Polytetrafluoroethylene, a crystalline polymer commonly known as Teflon, consists simply of a linear saturated fluorocarbon, i.e., linear polyethylene with all hydrogen atoms substituted by fluorine atoms.

$$
\left[-\mathrm{CF}_{2}-\mathrm{CF}_{2}-\right]_{\mathrm{n}}
$$


Polyvinylchloride (PVC)

Polyvinylchloride, PVC, is generally considered to be a non-crystalline polymer. Random stereoisomerism at the carbon atoms attached to the chlorines is accepted as the reason for the inability of this polymer to crystallize. The polymer structure is:

$$
\left[-\stackrel{\mathrm{CH}}{2}-\mathrm{CH}-_{n}\right.
$$

specific gravity 1.36

\section{Polychlorotrifluoroethylene (Kel-F)}

Polychlorotrifluoroethylene, Kel-F, has properties which are in many respects similar to Teflon to which it is structurally closely related. Alternate carbon atoms have a fluorine atom replaced with a chlorine.

$$
\left[\begin{array}{c}
\stackrel{\mathrm{Cl}}{!} \\
-\mathrm{CF}_{2}-\mathrm{CF}-
\end{array}\right] \mathrm{n}
$$

specific gravity 2.10

The substitution of a chlorine atom gives rise to possible stereoisomerism; however, apparently because of the close simjlarity in size of the chlorine and fluorine atoms it does not prevent crystallization, but does result in a much less, highly ordered organic crystalline structure.

\section{Epoxy Formulations}

The thermalsetting resins are basically Shell Epon 828 with variations in curing agents and fillers.

$$
\text { Epoxy 1478-1 }
$$

This formulation has the following composition:

Base Resin: 60 PBW*, Shell Epon 828

Filler: $40 \mathrm{PBW}, 4 \mathrm{x}$ mica

Curing agent: $7.2 \mathrm{PBW}$, diethanolamine (DEA) 
Curing time: 15 hours at $165^{\circ} \mathrm{F}$

Specific gravity: 1.52

The $4 \mathrm{x}$ mica filler used here is reinforcing.

Epoxy 1478-3

This formulation has the following composition:

Base resin: 100 PBW, Shell Epon 828

Filler: none

Curing agent: 7.2 PBW, diethanolamine (DEA)

Curing time: 15 hours at $165^{\circ} \mathrm{F}$

Specific gravity: 1.20

Epoxy 1478-22

This formulation has the following composition:

Base resin: 100 PBW, Shell Epon 828

Filler: none

Curing agent: $20 \mathrm{PBW}$, " $\mathrm{Z}$ "; i. e., eutectic of $\mathrm{H}, 4^{\prime}$ methtlene di-aniline and meta plenylene diamine

Curing time: 18 hours at room temperature +15 hours at $120^{\circ} \mathrm{F}+8$ hours at $212^{\circ} \mathrm{F}$

Specific gravity: 1.20 
APPENDIX D

SAMPLE IDENTIFICATION AND THICKNESS

\begin{tabular}{c} 
Material \\
Type \\
\hline
\end{tabular}

Polyethylene

Polystyrene

Polyvinylchloride

(PVC)

Polypropylene

Polytetrafluoroethylene (Teflon)

Nylon

Polychlorotrifluoroethylene (Kel-F)

\section{Sample}

No.

$\mathrm{N}-1$

$\mathrm{N}-2$

$\mathrm{N}-3$

$\mathrm{N}-5$

$\mathrm{N}-6$

$\mathrm{N}-7$

$\mathrm{N}-8$

$\mathrm{N}-10$

$\mathrm{N}-11$

$\mathrm{N}-12$

$\mathrm{K}-1$

$\mathrm{K}-2$

$\mathrm{K}-13$

$\mathrm{K}-14$

$\mathrm{K}-15$

$\mathrm{K}-16$

$\mathrm{K}-17$

$\mathrm{K}-18$

$\mathrm{K}-19$

$\mathrm{K}-20$

I-1

$I-2$

A-1

$A-3$

D-1

D-2

F-1

F-2

G-2

G-3
Thickness, $\mathrm{cm}$

0.160

0.160

0.165

0.151

0.152

0.152

0.165

0.162

0.156

0.146

0.137

0.143

0.157

0.160

0.160

0.159

0. 158

0.163

0.163

0.157

0. 321

0.314

0.324

0.325

0.332

0.335

0.265

0.268

0.165

0.165 
SAMPLE IDENTIFICATION AND THICKNESS (Continued)

Material

Type

Epoxy 1478-1

Epoxy 1478-3

Epoxy 1478-22
Sample

No.

M-1

$\mathrm{M}-2$

M-5

M-6

$\mathrm{M}-7$

M-10

M-11

M-12

M-13

$\mathrm{M}-16$

C-2

C-3

B-2

B-3
Thickness, $\mathrm{cm}$

0.152

0.119

0.313

0. 318

0.310

0.307

0. 310

0.313

0.306

0. 317

0.294

0.284

0.368

0.264 


\section{APPENDIX E \\ DISCUSSION OF LEAKAGE CURRENTS}

The successful elimination of leakage current was assured by experimental measurements. The proof of this leakage current elimination is as follows:

(1) The dark conductivity of each disc of all materials studied, including the encapsulating material, was measured before and after encapsulation. Symbolically, these measurements are

$$
\begin{aligned}
\sigma_{\mathrm{o}, \mathrm{x}, \mathrm{b}}= & \text { the dark conductivity }\left(\sigma_{\mathrm{o}}\right) \text { of } \\
& \text { material }(\mathrm{x}) \text { before encapsulation }(\mathrm{b})
\end{aligned}
$$

and

$$
\begin{aligned}
\sigma_{0, x, a}= & \text { the dark conductivity of the same } \\
& \text { material after encapsulation (a) }
\end{aligned}
$$

In all cases, within experimental error,

$$
\sigma_{o, x, b}=\sigma_{o, x, a}
$$

which demonstrated that no measurable leakage current passed through the encapsulating material under dark conditions.

(2) Equation $(E-1)$ is equal to

$$
\begin{gathered}
\sigma_{0, x, b}=\sigma_{0, x, a}=\sigma_{0, x} \\
\text { or } \\
\sigma_{0, x, b}=\sigma_{0, x, a}=\sigma_{0, \ell, x}=\sigma_{0, \ell}
\end{gathered}
$$

where $\sigma_{0, x}=$ the dark conductivity of any disc of material $x$.

$$
\sigma_{0, \ell, x}=\text { the dark conductivity of the encapsulating }
$$
material when used as a disc of material $x$, and is equal to $\sigma_{0, \ell}$, the dark conductivity of the material comprising the leakage path.

(3) The photoconductivities of each disc of all materials studied, including the encapsulating material, were measured in the encapsulated units during exposure. 
Symbolically these measurements gave

$$
\begin{aligned}
\sigma_{\mathbf{x}}= & \text { the photoconductivity }(\sigma) \text { of material }(\mathrm{x}) \text { at any given } \\
& \text { gamma-ray intensity }(\dot{\mathrm{R}})
\end{aligned}
$$

and

$\sigma_{\ell, x}=$ the photoconductivity of the encapsulation material when used as material $\mathrm{x}$ at any given gamma-ray intensity, and is also equal to $\sigma_{\ell}$, the conductivity of the leakage path under the same irradiation condition.

(4) The sufficient condition to assure that the leakage current in the encapsulating material did not contribute to the measurement of the photoconductivity of a material $x$ is shown in the Eq. (E-4).

$$
\frac{I_{\ell, x}}{I_{x}}=\frac{A \sigma_{\ell}+B \sigma_{\ell, x}}{A \sigma_{\ell}+B \sigma_{x}} \leq \frac{A \sigma_{0, \ell}+B \sigma_{0, \ell, x}}{A \sigma_{0, \ell}+B \sigma_{0, x}}=\frac{I_{0, \ell, x}}{I_{0, x}}
$$

where $I_{\ell, x}=$ the measured photocurrent in the encapsulating material when tested as disc $x . \quad I_{\ell, x}$ is related to conductivity by

$$
I_{\ell, x}=B \sigma_{\ell, x} V
$$

where $B$ is the effective area divided by the thickness of the disc of encapsulation material and $\mathrm{V}$ is the test voltage.

$I_{0, \ell, x}=$ the corresponding dark current in the encapsulating material when tested as a disc $\mathbf{x}$.

$I_{x}=$ the measured photocurrent in the disc of material $\mathbf{x}$ and is related to conductivity by

$$
I_{x}=B \sigma_{x} V
$$

where, as before, $B$ is the effective area divided by the thickness of the discs of any material $x$. 


$$
\begin{aligned}
I_{0, x}= & \text { the corresponding dark current in the discs } \\
& \text { of material } x,
\end{aligned}
$$

and

$$
A=\text { the effective area of the leakage path divided by }
$$
the effective length of the leakage path.

(5) The sufficient condition of Eq. $(E-4)$ reduces to

$$
\frac{I_{\ell, x}}{I_{x}}=\frac{{ }^{\sigma} \ell, x}{\sigma_{x}} \leq \frac{\sigma_{0, \ell, x}}{\sigma_{0, x}}=\frac{I_{0, \ell, x}}{I_{0, x}}
$$

since conductivity measurements revealed that the following conditions existed:

$$
\begin{aligned}
& \mathrm{B} \sigma_{\ell, x} \gg \mathrm{A} \sigma_{\ell} \\
& \mathrm{B} \sigma_{x} \gg \mathrm{A} \sigma_{\ell} \\
& \mathrm{B} \sigma_{0, \ell, \mathrm{x}} \gg \mathrm{A} \sigma_{0, \ell} \\
& \mathrm{B} \sigma_{0, \mathrm{x}} \gg \mathrm{A} \sigma_{0, \ell}
\end{aligned}
$$

(6) The sufficient condition of Eq. (E-7) must be satisfied for all levels of the radiation intensity to assure that leakage current is negligible for each encapsulated sample studied. 


\section{APPENDIX F \\ MATHEMATICAL FORMULATION OF THE PHOTOCONDUCTIVITY PROCESS IN SINGLE CRYSTAL PHOTOCONDUCTORS}

The framework for a mathematical formulation of the photoconductivity process is substantially the same as that effectively used in semiconductor junction device physics. ${ }^{29}$ Before presenting these mathematical functions it is necessary to make certain basic assumptions: (1) an ohmic contact exists at the photoconductor-electrode interface; (2) ionic currents are negligible; (3) photocarriers are produced by excitation from the valence to the conduction band (more simplified than the electronic transitions presented in Appendix B); and (4) the energy level scheme of Fig. F-1 is composed of a valence band, a conduction band, one type of donor and one type of acceptor level, and a single set of imperfection centers. The mathematical treatment based on these assumptions was first presented by Rittner (1954) ${ }^{30}$ and later published in a more abbreviated and summarized form by Bube (1960). 31 The equations governing the behavior of the free electrons, free holes, and trapped electrons associated with the abbreviated model of Fig. F-1 are as follows:

$$
\begin{aligned}
& \frac{\partial p}{\partial t}=-\frac{p-p_{o}}{\tau_{p}}+g_{v t}-r_{t v}+f-e^{-1} \operatorname{div} \vec{J}_{p} \\
& \frac{\partial n}{\partial t}=-\frac{n-n_{0}}{\tau_{n}}+g_{t c}-r_{c t}+f-e^{-1} \operatorname{div} \vec{J}_{n} \\
& \frac{\partial n_{t}}{\partial t}=r_{c t}-g_{t c}+g_{v t}-r_{t v}
\end{aligned}
$$

${ }^{29}$ Shockley, W., Electrons and Holes in Semiconductors, D. Van Nostrand Company, Inc., New York, (1959), Ch.12, p. 298.

${ }^{30}$ Rittner, E. S., Electron Processes in Photoconductors, Photoconductivity Conference, Atlantic City, 1954.

${ }^{31}$ Bube, R. H., op. cit., (Ref. 11, Ch.11, p. 235). 


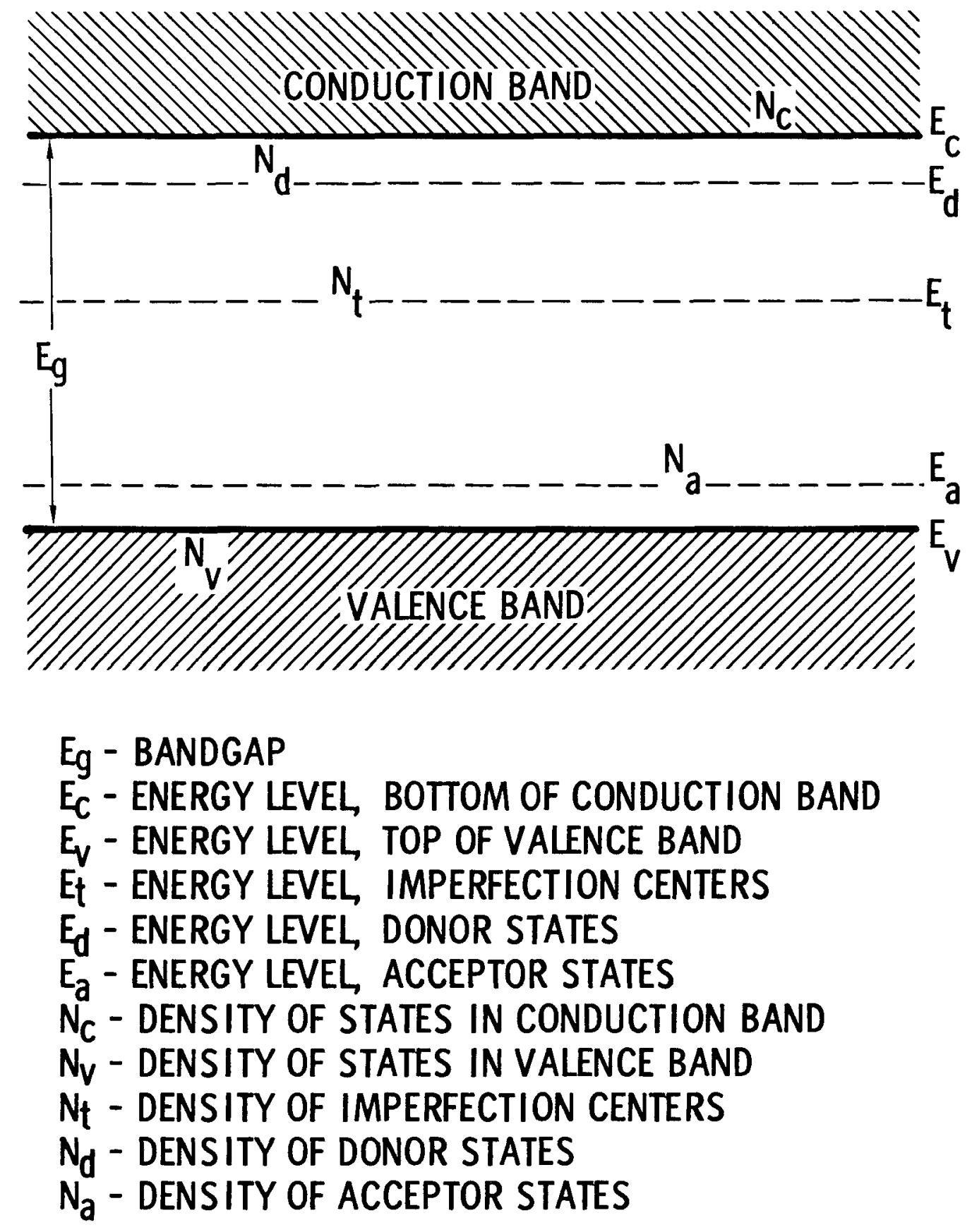

FIG. F-1. SIMPLIFIED ENERGY LEVEL DIAGRAM 


$$
\begin{aligned}
& \vec{J}_{p}=e \mu_{p} p \vec{E}-e D_{p} \operatorname{grad} p \\
& \vec{J}_{n}=e \mu_{n} n \vec{E}+e D_{n} \operatorname{grad} n \\
& \vec{J}=\vec{J}_{n}+\vec{J}_{p} \\
& \operatorname{div} \vec{E}=\frac{4 \pi q}{\epsilon}
\end{aligned}
$$

The seven equations just presented can be combined into four equations with four unknowns $\left(n, p, n_{t}\right.$, and $\left.q\right)$.

Equations $F-1$ and $F-2$ are the continuity equations for free holes and free electrons, respectively. The first term on the right represents the disappearance of free carriers by recombination. $\quad \tau_{p}$ and $\tau_{n}$ are hole and electron lifetimes, and $p_{0}$ and $n_{0}$ are the dark hole and dark electron densities. The lifetimes in general are considered concentration dependent. The second term represents the excitation of captured carriers with

$$
\begin{aligned}
& g_{v t}=\left(N_{t}-n_{t}\right) N_{v} S_{p} e^{-\left(E_{q}-E_{t}\right) / k T} \\
& g_{t c}=n_{t} N_{c} S_{n} e^{-E_{t} / k T}
\end{aligned}
$$

where $N_{t}$ is the density of imperfection centers, $n_{t}$ of which are occupied by electrons with capture cross section $S_{p}$ for a free hole when occupied by an electron, and with capture cross section $S_{n}$ for a free electron when unoccupied; and $\mathrm{v}$ is the thermal velocity of a free electron. The third term represents the capture of free carriers with

$$
\begin{aligned}
& r_{t v}=p n_{t} v S_{p} \\
& r_{c t}=n\left(N_{t}-n_{t}\right) v S_{n}
\end{aligned}
$$

The fourth term, f, represents the density of carriers generated per unit time by the incident photons. The fifth term represents the divergence of the current densities, i.e., the magnitude of charge flow across the photoconductorconductor interface. 
Equation F-3 is the continuity equation for electrons in the imperfection centers; excitation from or into these centers by photons has been neglected for this discussion. Equations F-4,F-5, and F-6 give, respectively, the definitions for the current density of holes, the current density of electrons, and the total current density. The current densities consist of two terms, the first a conduction term, and the second a diffusion term; where $\mu_{\mathrm{p}}$ and $\mu_{\mathrm{n}}$ are hole and electron mobility, $E$ is the electric field, and $D_{p}$ and $D_{n}$ (hole and electron diffusion constants) are from the Einstein relationships, where

$$
\begin{aligned}
& D_{p}=\frac{k T}{e} \mu_{p} \\
& D_{n}=\frac{k T}{e} \mu_{n}
\end{aligned}
$$

Equation F-7 is Poisson's relationship with q representing the space-charge density.

In order to reduce the mathematical complexity associated with the solution of Eqs. F-1 through F-7, certain assumptions can be made: (1) spacecharge effects may be neglected, i.e., $\mathrm{q}=0$ and $\Delta \mathrm{n}+\Delta \mathrm{n}_{\mathrm{t}}=\Delta \mathrm{p}$; and (2) electron and hole lifetimes are equal, i.e., $\tau_{\mathbf{n}}=\tau_{p}=\tau$. On substituting Eqs. F-4 and F-5 into Eqs. F-1 and F-2, F-14 is obtained.

$\frac{\partial p}{\partial t}=-\frac{\Delta p}{\tau}+g_{v t}-r_{v t}+f+D_{p} \operatorname{div} \operatorname{grad} p-\mu_{p} p \operatorname{div} \vec{E}-\mu_{p} \vec{E} \cdot \operatorname{grad} p$

$\frac{\partial n}{\partial t}=-\frac{\Delta n}{\tau}+g_{t c}-r_{c t}+f+D_{n} \operatorname{div} \operatorname{grad} n+\mu_{n} n \operatorname{div} \vec{E}+\mu_{n} \vec{E} \cdot \operatorname{grad} n$

Now multiplying Eq. F-14 by the quantity $\mu_{n} n$ and Eq. F-15 by $\mu_{p}$; adding to eliminate $\operatorname{div} \mathrm{E}$ terms; and with subsequent use of Eq. F-3, above assumption (1), and the following relationships

$$
\begin{gathered}
\Delta n+\Delta n_{t}=\Delta p \\
\frac{\partial n}{\partial t}+\frac{\partial n_{t}}{\partial t}=\frac{\partial p}{\partial t}=\frac{\partial \Delta p}{\partial t}
\end{gathered}
$$

$\operatorname{grad} \mathrm{n}+\operatorname{grad} \mathrm{n}_{\mathrm{t}}=\operatorname{grad} \mathrm{p}=\operatorname{grad} \Delta \mathrm{p}$ 
The following equation is obtained

$$
\begin{aligned}
\frac{\partial \Delta \mathrm{p}}{\partial t}= & -\frac{\Delta p}{\tau}+\frac{\gamma \Delta \mathrm{n}_{\mathrm{t}}}{\tau}+\mathrm{g}_{\mathrm{vt}}-\mathrm{r}_{\mathrm{tv}}+\mathrm{f}+\mathrm{D} \operatorname{div} \operatorname{grad} \Delta \mathrm{p} \\
& -\gamma \mathrm{D}_{\mathrm{n}} \operatorname{div} \operatorname{grad} \Delta \mathrm{n}_{\mathrm{t}}+\mu * \overrightarrow{\mathrm{E}} \cdot \operatorname{grad} \Delta \mathrm{p}-\gamma \mu_{\mathrm{n}} \overrightarrow{\mathrm{E}} \cdot \operatorname{grad} \Delta \mathrm{n}_{\mathrm{t}}
\end{aligned}
$$

where

$$
\begin{aligned}
\gamma & =\frac{1}{1+\mu_{n} n / \mu_{p} p} \\
D & =\frac{n+p}{n / D_{p}+p / D_{n}} \\
\mu^{*} & =\frac{p-n}{n / \mu_{p}-p / \mu_{n}}
\end{aligned}
$$

In Eq. F-17 there are three unknowns: $\Delta \mathrm{n}, \Delta \mathrm{p}$, and $\Delta \mathrm{n}_{\mathrm{t}} \cdot$ There are also three equations relating these unknowns: Eqs. F-17, F-16, and F-3. In general, the task of finding a solution to Eq. F-17 satisfying appropriate boundary conditions is a quite formidable one because of the nonlinear nature of the differential equation. However, by imposing additional restrictions, useful solutions possessing a limited range of validity can be obtained.

One such restriction, neglecting impurity states, reduces Eq. F-17. by eliminating the $g, r$, and $\Delta n_{t}$ terms and gives

$$
\frac{\partial \Delta \mathrm{p}}{\partial \mathrm{t}}=-\frac{\Delta \mathrm{p}}{\tau}+\mathrm{f}+\mathrm{D} \operatorname{div} \operatorname{grad} \Delta \mathrm{p}+\mu * \overline{\mathrm{E}} \cdot \operatorname{grad} \Delta \mathrm{p}
$$

Since this equation is still nonlinear because of the dependence of $\tau, D$, and $\mu *$ on $\mathrm{n}$ and $\mathrm{p}$, additional simplification is desirable. If diffusion effects are neglected, i.e., neglect end effects in a uniformly excited, homogeneous photoconductor, so that $\operatorname{grad} \Delta \mathrm{p}=0$, then

$$
\frac{\mathrm{d} \Delta \mathrm{p}}{\mathrm{dt}}=-\frac{\Delta \mathrm{p}}{\tau}+\mathrm{f}
$$


This equation for hole generation under steady-state conditions reduces to

$$
\mathrm{f}_{\mathrm{p}}=\Delta \mathrm{p}
$$

and conversely for electron generation using a similar method of solution

$$
\boldsymbol{f}_{\mathbf{n}}=\Delta \mathrm{n}
$$

where $\boldsymbol{\tau}_{\mathbf{n}}$ is the free lifetime of an electron, $\boldsymbol{\tau}_{\mathbf{p}}$ is the free lifetime of a hole, and $\Delta \mathrm{n}$ and $\Delta \mathrm{p}$ are, respectively, the additional free-electron and freehole densities present as a result of the absorption of photons. The incremental conductivity can now be written as

or

$$
\Delta \sigma=\mathrm{e} \mu_{\mathrm{n}} \Delta \mathrm{n}+\mathrm{e} \mu_{\mathrm{p}} \Delta \mathrm{p}
$$

$$
\Delta \sigma=f e\left(\mu_{n} \tau_{n}+\mu_{p} \tau_{p}\right)
$$

This relationship shows why the lifetime is a key parameter in photoconductivity and that, in this instance, incremental conductivity is directly proportional to the first power of $f$.

This simplified mathematical description of the photoconductivity process indicates the complexities of a complete solution, assuming photoconductivity material was available whose device physics was quantitatively understood and defined. In the case of organic insulating material whose photoconductivity properties are not explicitly defined and well understood, the situation is distinctly more complicated. An example is the inability, at the present time, to measure the Hall mobilities, $\mu_{h}$, of low-conductivity organic dielectrics. Therefore, the effective combination of Hall effect and conductivity measurements to determine the concentration and mobility of the charge carriers is not possible. Consequently, no distinction can be drawn as to which of the two carriers is the majority or the minority carrier. The measurement of conductivity gives only $\mathrm{e}\left(\mathrm{n} \mu_{\mathrm{n}}+\mathrm{p} \mu_{\mathrm{p}}\right)$.

The application of the basic continuity equations ( $F-1$ through $F-7)$ to the photoconductivity phenomena in organic dielectrics is valid and can be used to give a qualitative understanding of the processes involved. 


\section{APPENDIX G}

\section{MODELS WHICH FIT MEASURED PHOTOCONDUCTIVITY PHENOMENA}

From a mathematical viewpoint, Appendix F discussed a simplified photoconductivity model with one type of donor and one type of acceptor level, and a single set of imperfection centers. This appendix will discuss models which better classify and describe observed photoconductivity behavior in organic dielectrics. The material for this discussion is based on a publication by Rose 32 which discusses photoconductivity processes and on a publication by Fowler, ${ }^{33}$ extending the publication by Rose, which explains measured photoconductivities in amorphous and semicrystalline insulating materials. The following models draw heavily on the depth and distribution of traps (imperfection centers) in the forbidden region, assume a conventional band structure, and assume conduction by electrons only.

Let the traps be distributed in exponential decreasing numbers below the conduction band such that the energy distribution is given by

$$
n_{E_{x}} d E_{x}=A e^{-E_{x} / k T_{1}} d E_{x}
$$

Such a distribution is presented in Fig. G-1. The temperature $T_{1}$ is used here to indicate a temperature higher than room temperature. Physically, $T_{1}$ is considered to be the temperature at which the traps were "frozen in" as the polymer structure was formed. Therefore, $A$ and $T_{1}$ are constants for a given material, $\mathrm{E}_{\mathbf{x}}$ is the photoconductivity activation energy, and $\mathrm{n}_{\mathrm{E}_{\mathbf{x}}}$ is the number of traps per unit volume per unit energy depth.

The number of electrons, $n_{t}$, trapped below $E_{x}$ is equal to the number of traps, $N_{t}$, below $E_{x}$ and is a good approximation of the number of holes.

\footnotetext{
${ }^{32}$ Rose, A., op. cit. (Ref. 1). ${ }^{33}$ Fowler, J. F., op. cit., (Ref. 2).
} 

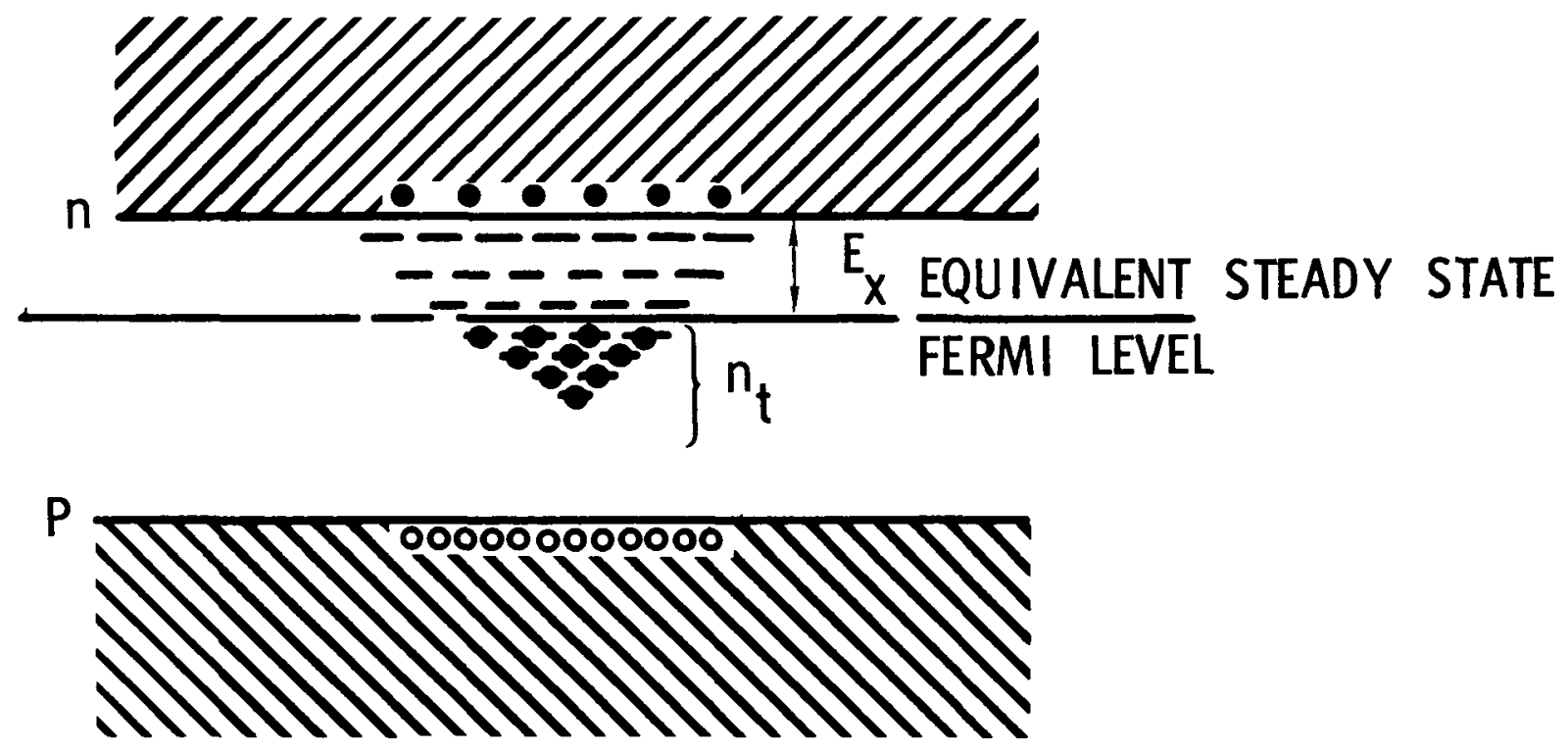

FIG. G-1.EXPONENTIAL TRAP DISTRIBUTION. 
p, i.e., $n_{t}=N_{t}$ and $p=n+n_{t} \approx n_{t}$. Thus,

$$
\begin{aligned}
\mathrm{p} \approx \mathrm{n}_{\mathrm{t}} & =\int_{\mathrm{E}_{x}}^{\infty} A \mathrm{e}^{-\mathrm{E}_{x} / k \mathrm{~T}_{1}} d \mathrm{E}_{\mathrm{x}} \\
& =A k \mathrm{~T}_{1} \mathrm{e}^{-\mathrm{E}_{x} / k \mathrm{~T}_{1}}=B \mathrm{~T}_{1} \mathrm{e}^{-\mathrm{E}_{\mathrm{x}} / k \mathrm{~T}_{1}}
\end{aligned}
$$

now combining $\mathrm{p}$ with the following expression for the number of conduction electrons, $n$, under steady-state conditions

$$
\mathrm{n}=\mathrm{f} / \mathrm{vsp}
$$

Eq. $\mathrm{G}-4$ is obtained

$$
\mathrm{n}=\mathrm{f} / \mathrm{vsBT} \mathrm{T}_{1} \mathrm{e}^{-\mathrm{E}_{\mathrm{x}} / \mathrm{kT} \mathrm{T}_{1}}
$$

where $\mathrm{v}$ is the thermal velocity of a free electron and $\mathrm{s}$ is the capture cross section of holes for free electrons. The value of the photoconductivity activation energy, $E_{x}$, is commonly given by

$$
n=N e^{-E_{x} / k T}
$$

or

now combining Eqs. G-4 and G-6 gives

$$
E_{x}=k T \ln N / n
$$

$$
\mathrm{n}=\mathrm{f} / \operatorname{vsBT}_{1}\left(\frac{\mathrm{n}}{\mathrm{N}}\right)^{\mathrm{T} / \mathrm{T}_{1}}
$$

or in aslightly more useful form solving for $n$

$$
n=\left[f / v s B T_{1} N-T / T_{1}\right]^{T_{1} /\left(T * T_{1}\right)}
$$

If $T_{1}=T, n$ (the photocurrent and the photoconductivity) increases as the square root of the light intensity. In brief, an exponential trap distribution in energy below the conduction band can yield a range of exponents between 0.50 and 1.00 for conductivity versus photo intensity depending on the temperature, $T_{1}$, at which the traps were "frozen in." Being consistant with our notation for gamma-ray photoconductivity,

$$
\sigma=\sigma_{0}^{\circ} \dot{R}^{\delta}=\sigma_{0}^{\prime} \dot{R}^{T_{1} /\left(T+T_{1}\right)}
$$


where $\delta=\mathrm{T}_{1} /\left(\mathrm{T}+\mathrm{T}_{1}\right) . \quad \delta \rightarrow 0.50$ for an exponential trap distribution, $\mathrm{T}_{1}$ low, and $\mathrm{T} \approx \mathrm{T}_{1}$.

$\delta \rightarrow 1.00$ for a uniformly distributed trap depth in energy below the conduction band. The energy diagram for such an assumed distribution is presented in Fig. G-2. The energy distribution function is

$$
\mathrm{n}_{E_{\mathbf{x}}} \mathrm{d} \mathrm{E}_{\mathbf{x}}=\text { constant } \mathrm{dE}
$$

and as in the above case $\mathrm{p}=\mathrm{n}+\mathrm{n}_{\mathrm{t}} \approx \mathrm{n}_{\mathrm{t}}$. Thus

$$
\mathrm{p} \approx \mathrm{n}_{\mathrm{t}}=\text { constant }
$$

Combining $\mathrm{p}$ with the expression for conduction electrons, $\mathrm{n}$,

$$
\mathrm{n} \approx \mathrm{f} / \mathrm{vsp}
$$

it follows that $\mathrm{n}$ (the photocurrent and the photoconductivity) increases linearily with light intensity and for Eq. G-9 $\delta=1.00$.

These two models have been used in the past to explain measured behavior when $0.50 \leq \delta \leq 1.00$. The band structure of Figs. G-1 and G-2 is used for convenience. Fowler has suggested that a discontinuous band structure, as shown in Fig. G-3, is more appropriate for the amorphous and semicrystalline organic insulators of this work. This structure predicts that the conduction levels of one spatially located group of atoms may be the trapping levels for a neighboring spatially located group and vice versa. 



FIG. G-2.UNIFORM TRAP DISTRIBUTION. 


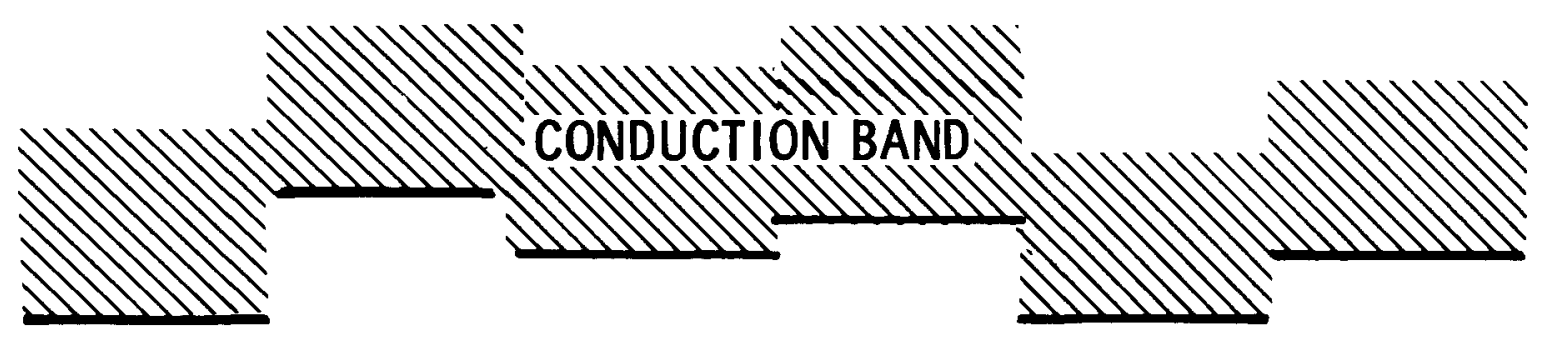

BAND GAP

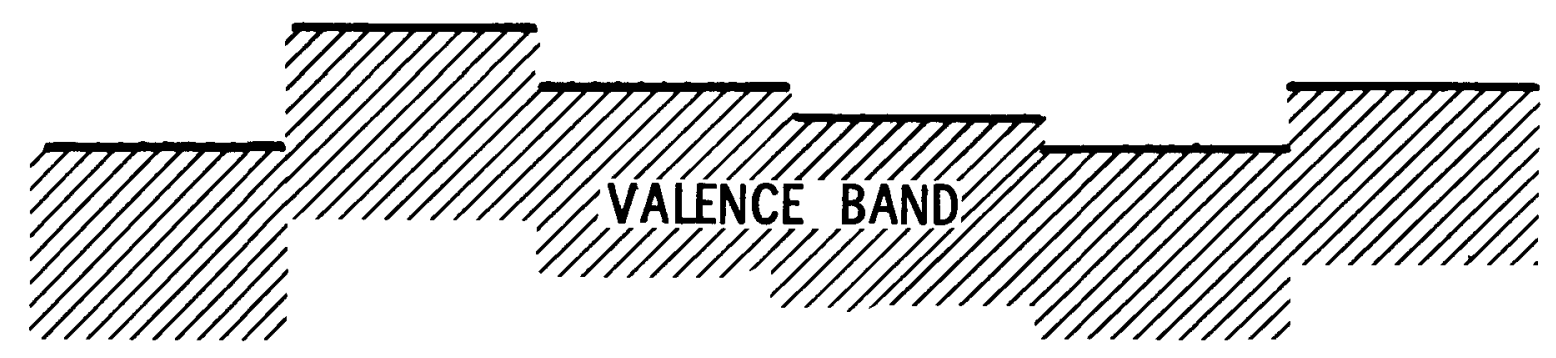

FIG. G-3. DISCONTINUOUS BAND STRUCTURE OF AMORPHOUS AND SEMICRYSTALLINE ORGANIC INSULATORS AS SUGGESTED BY FOWLER. 


\section{APPENDIX H-RATE OF IONIZATION}

The one distinct difference between gamma-ray photoconductivity in organic insulating material and visible light photoconductivity in singlecrystal inorganic materials is the number of ionizations per absorbed photon. In the latter case, the ratio is generally assumed to be 1 to 1 ; $i_{\text {. e. , }}$ for each photon absorbed by the material, one ion pair is formed. 34,35 For gamma rays the ionized electrons have a "fast energy" associated with them. This excess kinetic energy is dissipated in secondary collisions and the resulting electron-electron interactions produce charge carriers. Thus, the common property of gamma-ray photons is that the amount of energy carried by each is approximately five orders of magnitude greater than that binding an orbital electron to its nucleus or an atom to its neighbor. These energies will usually be less than that required to affect the binding force within the atomic nucleus. In reality, gamma-ray photons lose most of their energy by interaction with orbital electrons to produce ions, free electrons, and excited atoms or molecules. Seitz and Kuehler ${ }^{36}$ have quoted a value of only 1 percent for the amount of energy lost in other ways.

Charlesby ${ }^{37}$ quotes a figure for the average energy required per ion pair formed in air. This figure is $34 \mathrm{ev}$. In their passage through air, gamma rays produce ionization of the gas molecules and render the air conductive. The 34-ev energy is considerably greater than the minimum energy required to ionize either a neutral oxygen $\left(0_{2}-12.2 \mathrm{ev}\right)$ or nitrogen $\left(\mathrm{N}_{2}-15.6 \mathrm{ev}\right)$ molecule. ${ }^{38}$ The remaining energy absorbed is dissipated

${ }^{34}$ Sproull, R. L., op. cit., (Ref. 21, Ch. 10, p. 304).

${ }^{35}$ Kittel, C. , Introduction to Solid State Physics, John Wiley and Sons, Inc., New York, 1957, Second Edition, Ch.18, p. 512.

${ }^{36}$ Seitz, F., and Koehler, J. S., International Conference on Peaceful Uses of Atomic Energy, Geneva 7, 615, 1955.

${ }^{37}$ Charlesby, A, , op. cit., (Ref. 19, Ch. 2).

${ }^{38}$ Charlesby, A., op. cit., (Ref. 19, p. 19). 
in the form of electronic excitation, kinetic energy, or heat. The number of excited molecules produced cannot be measured, but Charlesby estimates that in many cases the total absorbed energy is shared between ionization and excitation in roughly equal amounts.

In liquids and solids, the measurement of ionization is greatly complicated by the close proximity of neighboring molecules or atoms. This allows reactions between ions, free electrons, and excited atoms or molecules to proceed very rapidly. The primary yield of ions cannot be measured directly, and in this work on organics it is assumed to be the same as air, $34 \mathrm{ev}$.

Based on the above discussion and the assumed quantity of $34 \mathrm{ev}$, the following relationship was developed for the rate of ionization in a given material.

$$
F=\frac{\mathrm{KR} \rho \mathrm{V}}{34}
$$

where $\mathrm{F}=$ ionization rate, no. $/ \mathrm{sec}$

$$
\begin{aligned}
\ddot{\mathrm{R}} & =\text { dose rate, } \mathrm{rads} / \mathrm{sec}\left(\mathrm{rad}=100 \mathrm{ergs} / \mathrm{gm}=6.24 \times 10^{13} \mathrm{ev} / \mathrm{gm}\right) \\
\rho & =\text { density, } \mathrm{gm} / \mathrm{cm}^{3} \\
\mathrm{~V} & =\text { volume, } \mathrm{cm}^{3} \\
\mathrm{~K} & =\text { constant, } 6.24 \times 10^{13} \mathrm{ev} / \mathrm{gm}-\mathrm{rad} \\
34 & =\text { constant, ev } / \text { ionization }
\end{aligned}
$$




\section{APPENDIX I}

\section{THERMAL ACTIVATION ENERGIES}

\section{AND PHOTOCONDUCTIVITY ACTIVATION ENERGIES}

Conductivity varies with temperature under both dark and photoinduced conductivity conditions according to the general relationship

$$
\sigma=\sigma_{0} e^{-E / k T}
$$

where $\mathbf{E}=\mathrm{E}_{\mathrm{o}}$ the thermal activation energy for dark conductivity, or $E=E_{x}$ the thermal activation for photoconductivity. Measured values of $E_{0}$ and $E_{x}$ are presented in Fig. I-1 for Epoxy 1478-1, Fig. I-2 for polyethylene, and Fig. I-3 for polystyrene. $E_{x}$ for the epoxy, as shown in Fig. 5, is a function of the region in question. $E_{\mathbf{x}}$ for polyethylene and polystyrene is constant for the gamma-ray intensity limits of this work.

$E_{0}$ or $E_{x}$ is calculated by knowing the sets of boundary conditions, $\left(T_{a}, \sigma_{a}\right)$ and $\left(T_{b}, \sigma_{b}\right)$, which are taken from data plots of conductivity versus (absolute temperature), , $^{-1}$ and by manipulation of Eq. I-1, i.e.,

$$
\sigma=\sigma_{0} e^{-E / k T}
$$

or

$$
\ln \sigma=\ln \sigma_{0}-\mathrm{E} / \mathrm{kT}
$$

then

$$
\mathrm{E} / \mathrm{kT}=\ln \sigma_{0}-\ln \sigma
$$

and

$$
\ln \sigma_{0}=\ln \sigma+\mathrm{E} / \mathrm{kT}
$$

In Eq. I-2 boundary condition $\left(T_{a}, \sigma_{a}\right)$ gives

$$
\mathrm{E} / \mathrm{kT} \mathrm{T}_{\mathrm{a}}=\ln \sigma_{\mathrm{o}}-\ln \sigma_{\mathrm{a}}
$$

and in Eq. I-3 boundary condition $\left(T_{b}, \sigma_{b}\right)$ gives

$$
\ln \sigma_{0}=\ln \sigma_{b}+E / k T_{b}
$$




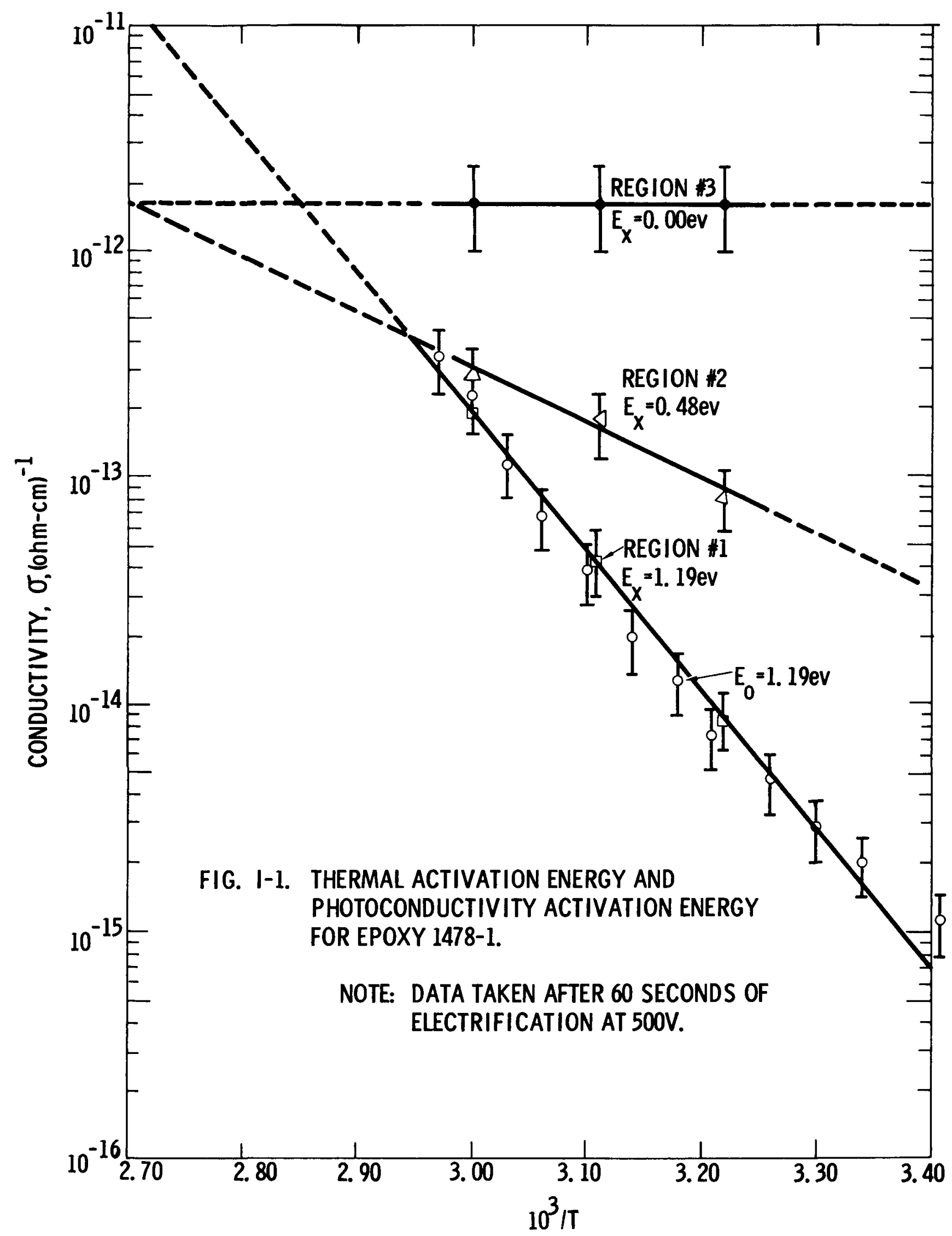




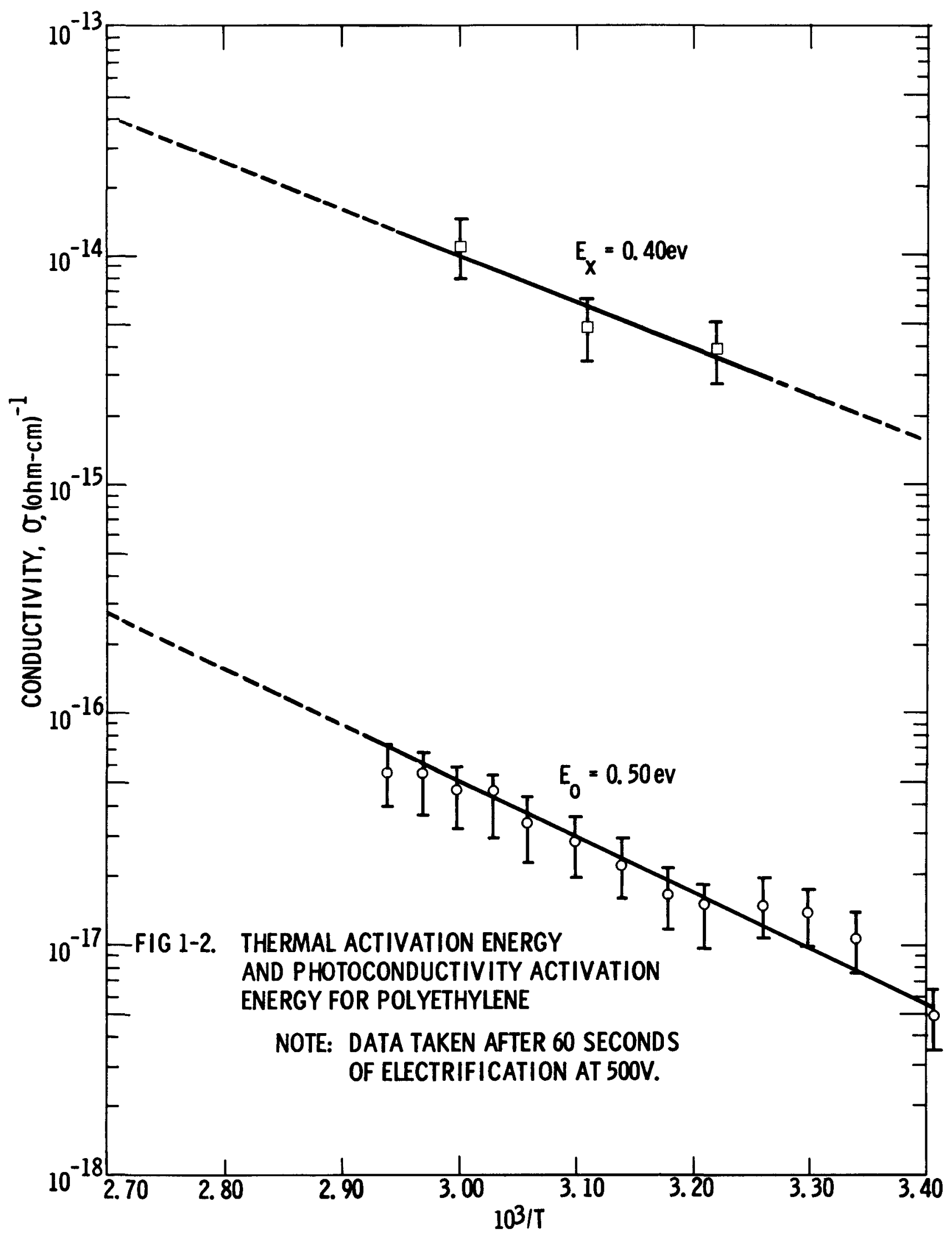




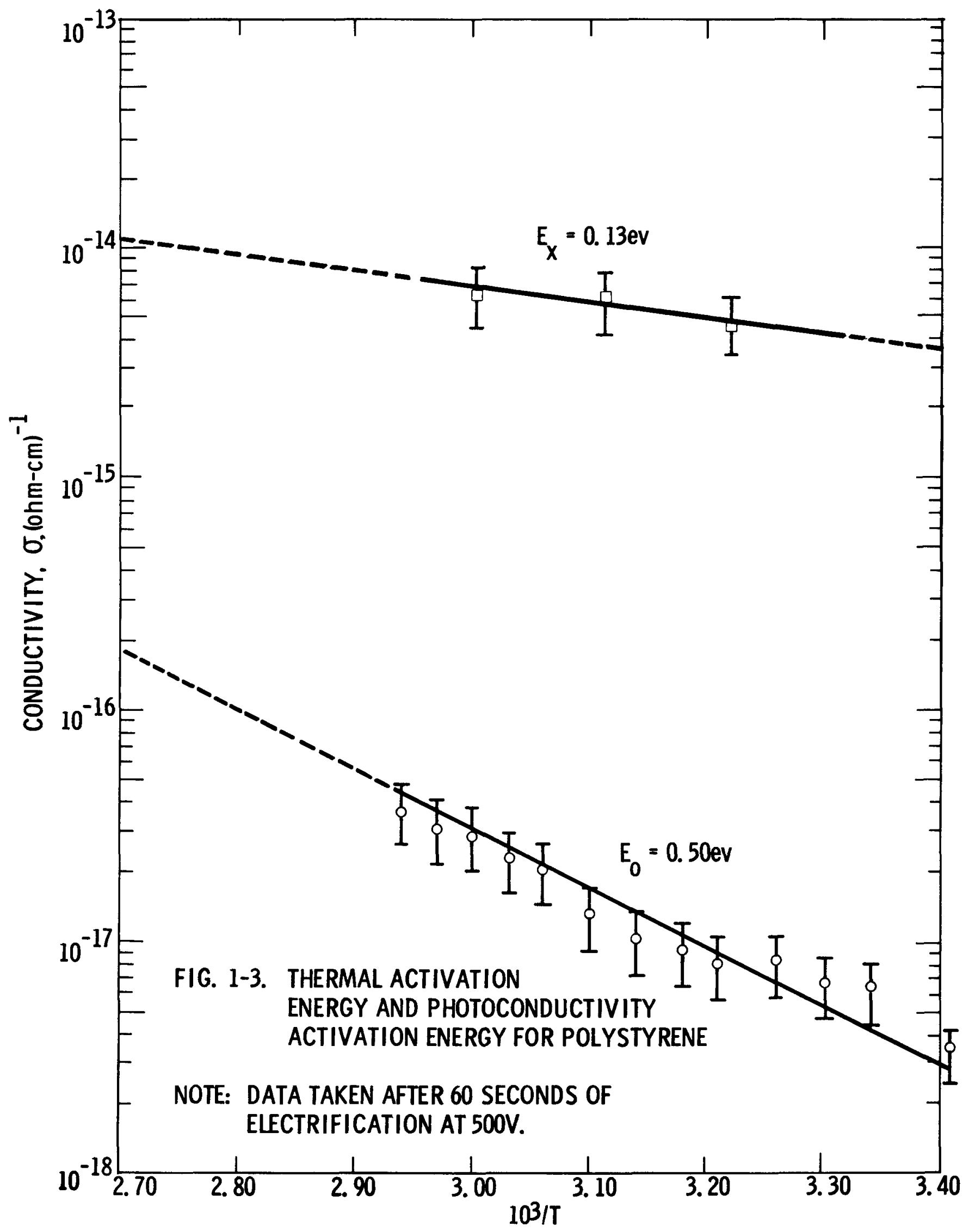


The combining of Eqs. I-4 and I-5 gives

$$
\mathrm{E} / \mathrm{kT} \mathrm{T}_{\mathrm{a}}=\ln \sigma_{\mathrm{b}}+\mathrm{E} / \mathrm{kT} \mathrm{T}_{\mathrm{b}}-\ln \sigma_{\mathrm{a}}
$$

or

$$
\frac{E}{k}\left[\frac{1}{T_{a}}-\frac{1}{T_{b}}\right]=\ln \sigma_{b}-\ln \sigma_{a}
$$

The solution for $\mathrm{E}$, which is either $\mathrm{E}_{\mathrm{o}}$ or $\mathrm{E}_{\mathbf{x}}$, gives

$$
E=\frac{k\left[\ln \sigma_{b}-\ln \sigma_{a}\right]}{\left[1 / T_{a}-1 / T_{b}\right]}
$$

where $\mathrm{k}=8.62 \times 10^{-5} \mathrm{ev} /{ }^{\circ} \mathrm{K}$ 